\title{
LA NECRÓPOLIS DEL BANCAL DEL ESTANCO VIEJO (MINATEDA-HELLÍN, ALBACETE)
}

\author{
JAVIER LÓPEZ PRECIOSO \\ FELICIANA SALA SELLÉS
}

Universidad de Alicante

\begin{abstract}
Una excavación realizada en 1915 puso al descubierto varias tumbas ibéricas en las cercanías del Tolmo de Minateda. Los autores identifican cada tumba y sus materiales, y concluyen que se trata de una necrópolis que fue utilizada entre comienzos del siglo $\mathrm{V}$ a.C. y el cambio de Era.

During an excavation carried out in 1915, several tombs from the Iberic Period were discovered. The authors try to identify each tomb and its materials, and conclude that this necropolis was visited from the early $V$ century b.C. to the beginning of our Era.
\end{abstract}

\section{INTRODUCCIÓN}

El inicio de las excavaciones sistemáticas en el "Tolmo de Minateda» (1) puso de manifiesto la necesidad de revisar los restos arqueológicos depositados en los fondos del Museo de Albacete que se han ido acumulando a lo largo de 75 años de investigación. En la mayor parte de los casos, los materiales proceden de hallazgos casuales o se caracterizan por la falta de un registro arqueológico. En otros, la dispersión de los objetos, justificada por la antigüedad de las excavaciones, ha contribuido a dificultar la interpretación de la información conservada.

La necrópolis fue descubierta por F. de Motos entre el 17 de abril y el 17 de mayo de 1915, según se afirma en la correspondencia publicada entre este investigador y Breuil (RIPOLL PERELLÓ, 1988), siendo excavada en este mismo período de tiempo. De los trabajos realizados no queda diario o anotaciones de ningún tipo, sólo en el momento de las gestiones de venta del material al Museo Provincial de Albacete se especifican algunas características de los enterramientos. En los archivos del Museo se

(1) Desde el año 1988 se vienen realizando trabajos de campo en dicho yacimiento a cargo de un equipo conjunto formado por miembros del Museo de Albacete y de la Universidad de Alicante. Agradecemos al Dr. L. Abad Casal y a Dña. R. Sanz Gamo la oportunidad brindada para realizar el estudio de esta necrópolis, en especial de doña R. Sanz, que amablemente nos facilitó el acceso al material y a los diarios. Agradecemos de igual modo la colaboración de Adoración Martínez Carmona en la realización de los dibujos. 
conservan papeles manuscritos de F. de Motos donde se da una relación de los ajuares y, en algún caso, el tipo de fosa u hoyo donde se realizó la deposición. De todos modos, se trata de una información que hay que tomar con cierta reserva puesto que son referencias hechas en 1928, es decir, 14 años después de las excavaciones.

En 1942 se reanudan las excavaciones, concentrándose los trabajos tanto en el Reguerón, barranco natural que sirve de acceso a la plataforma superior del Tolmo, como en la parte alta del mismo. De manera simultánea, García y Bellido procedió a realizar excavaciones en el lugar de la necrópolis exhumando tres enterramientos más (SÁNCHEZ JIMÉNEZ, 1947, 59 y 60), que no figuran en el registro del Museo Provincial, y cuyos diarios, encontrados recientemente, dan poca información.

En 1988, a raíz del descubrimiento de las inscripciones del Tolmo que motivaron el inicio de las excavaciones actuales, se procedió al cribado de las terreras de las obras de canalización que atravesaban los terrenos de la necrópolis, localizando diversos fragmentos de cerámica de barniz negro ática $\mathrm{y}$ dos fusayolas decoradas.

Tal y como se ha apuntado más arriba, las excavaciones sistemáticas en el Tolmo de Minateda se contemplan como parte de un proyecto global de investigación sobre el yacimiento y su incidencia en el proceso cultural de la comarca. Un aspecto importante de dicho proyecto es la revisión de los fondos antiguos del Museo de Albacete pertenecientes a este yacimiento, dentro del cual se incluye el estudio de la necrópolis del «Bancal del Estanco Viejo».

\section{LOCALIZACIÓN Y ENTORNO GEOGRÁFICO}

La comarca de Hellín-Tobarra se localiza al sur de la provincia de Albacete limitando con el área de la Sierra de Albacete al oeste, los Llanos al norte, Montealegre y Almansa al este, y los términos de Calasparra y Cieza (Murcia) al sur (Fig. 1 y 2).

Geográficamente queda definida por una serie de sierras que establecen unas fronteras naturales. Las vías de penetración y comunicación son trazadas a través de los ejes fluviales y de los pasos resultantes de la orografía. En primer lugar, debemos señalar la vía que se dirige hacia la zona de Cieza y por extensión hacia la costa murciana, marcada

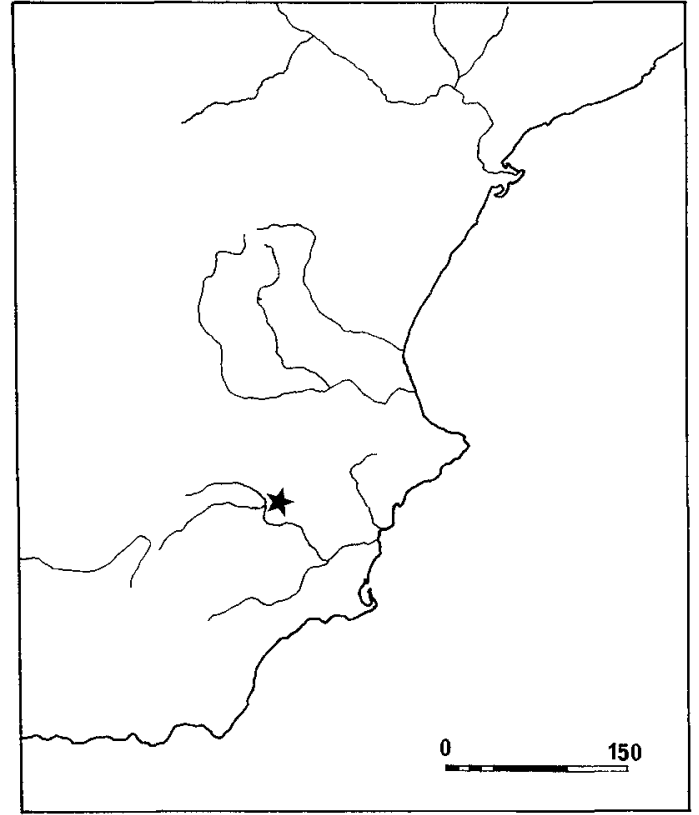

Fig. 1.- Localización del yacimiento.

por el río Segura y el Mundo. Ambos ríos verifican una bifurcación del mencionado camino, hacia la Sierra de Segura por Elche de la Sierra y Yeste en primer lugar, y hacia Lietor y Ayna en segundo término. En segundo lugar, desde la zona del pantano de Camarillas se señala otra vía de penetración ha-

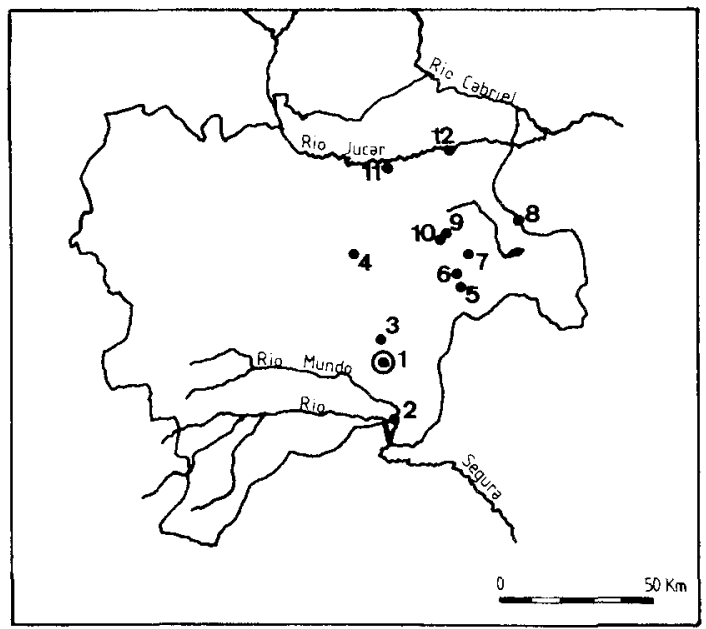

Fig. 2.- Yacimientos de la comarca. 1. Tolmo de Minateda y Bancal del Estanco Viejo. 2. Tesorico. 3. Hoya de Santa Ana. 4. Pozo Moro. 5. Cerro de los Santos. 6. Llano de la Consolación. 7. Amarejo. 8. Meca. 9. Los Villares. 10. Camino de la Cruz. 11. Casa del Monte. 12. Casa Grande. 
cia el norte por el arroyo de Tobarra, atravesando el valle de Minateda-Agramón. En este espacio se ubiça la necrópolis del Bancal del Estanco Viejo y su hábitat correspondiente: el Tolmo de Minateda. El camino proseguiría por el mencionado arroyo hasta llegar a las inmediaciones de Tobarra, desde donde se realiza el paso a los Llanos de Albacete por la Sierra de Navajuelos o bien por la Hoya de Santa Ana. Asimismo se establece una vía que podríamos considerar secundaria hacia el Cerro de los Santos, a través de la Cañada de Ortigosa, camino que vendría a ser la continuación del que proviene de la zona de Cástulo.

El Tolmo de Minateda está situado en la margen izquierda del arroyo de Tobarra, entre éste y la carretera nacional Albacete-Murcia, a unos $10 \mathrm{Km}$. de Hellín. La necrópolis se halla frente a él, en su lado sur, en la margen contraria del arroyo. Los terrenos que antaño ocupó son explotados en la actualidad con plantaciones de cereales y almendros, por lo que creemos que el conjunto debe estar bastante alterado (Fig. 3).

\section{LOS DATOS DE LA EXCAVACIÓN}

En el Museo de Albacete pudimos localizar la correspondencia que intercambiaron Federico de Motos y la Diputación con el fin de efectuar la compra de los objetos que este investigador obtuvo de las excavaciones en la necrópolis. En la primera carta adjunta una relación ordenada por sepulturas en la que ofrece algunos datos sobre el rito y tipo de tumba:

Sepultura 1. «Romana por inhumación encontrada entre las ibéricas, se reducía a una pequeña sepultura cavada en el terreno tapada con piedras planas, conteniendo el esqueleto de un niño y el ajuar...».

Sepultura 2. «Romana por inhumación, sepultura de un metro de larga por cuarenta centímetros de anchura y cincuenta de profundidad cavada en el terreno y perfectamente enlucida en el interior con barro amasado con paja, tapada con losas no conteniendo por lo tanto ninguna tierra como todas las encontradas, en su interior había un esqueleto de mujer adulta de ochenta y cuatro centímetros de altura bien conservado y como ajuar...».

Sepultura 3. «Como las anteriores contenía un esqueleto y el ajuar...».

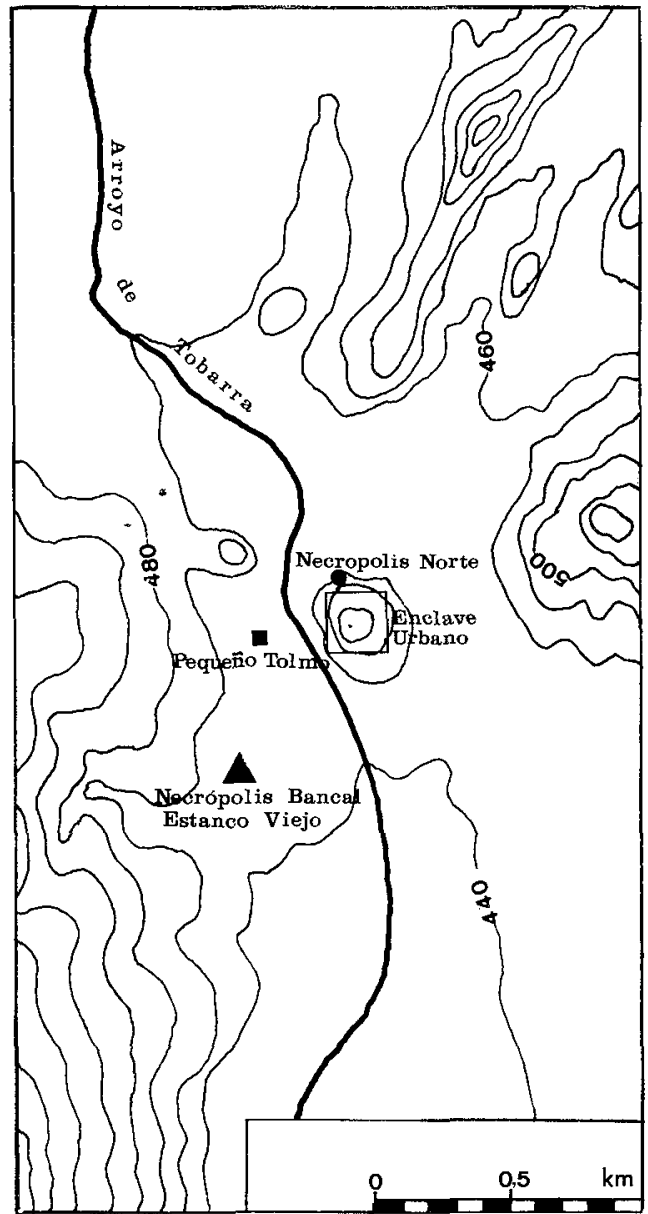

Fig. 3.- Situación de la necrópolis.

Sepultura 4. «Por incineración alrededor de la urna donde había señales de una fuerte hoguera por la abundancia de carbones y cenizas y por el estado de los objetos». Encontró fuera de la urna fragmentos de falcata, de soliferreum y otros informes de hierro; dentro de aquélla, una fíbula, un anillo y una fusayola.

Sepultura 5. «Como la anterior entre cenizas y carbones...», junto a la urna, tapada con un plato estaba una falcata, una lanza y hierros informes; dentro una fusayola y fragmentos de fíbula.

Sepultura 6. No especifica tipo alguno de sistema de enterramiento, en cambio sí señala la posición de los materiales: fuera de la urna, una lanza y trozos de un filete de caballo; dentro, la fíbula, una fusayola y pequeños fragmentos de bronce.

Sepultura 7. Sólo señala al exterior de la urna, una falcata, una lanza, trozos de regatón y fragmentos informes de hierro. 
Sepultura 8. «Alrededor de la urna cuchillos y al parecer navajas... dentro... trozos de fíbula y pegados a los huesos pequeños pedazos de bronce quizás pulseras».

Sepultura 9. No hay datos sobre el sistema de enterramiento o la posición.

Sepultura 10. Al igual que en la anterior, no hay datos.

Sepultura 11. «Alrededor trozos de falcata, trozos de lanza y un peso de barro, dentro... (el resto del ajuar)».

Sepultura 12. «La urna tapada con otro trozo de urna... alrededor sólo había ceniza y dentro... varios trozos de fíbula, una casi entera, una fusayola y tres cuentas de distintos materiales y una moneda, la única encontrada».

Sepultura 13. «Se encontró la urna rota debido a operaciones agrícolas... por lo superficial que estaba, dentro entre tierra y huesos, una fusayola y otro objeto de barro con un agujero, y a distancia trozos de hierro alguno de lanza».

Sepultura 14,15 y 16 . «Son trozos de vasijas pintadas encontrados junto a la necrópolis, no contenían nada».

Sepultura 17. «¿Peso de telar?. Encontrado junto a los números anteriores».

\section{INVENTARIO GENERAL DE LOS MATERIALES ARQUEOLÓGICOS DE LA NECRÓPOLIS (2)}

\section{Sepultura 1}

814. «Plato de barro negro».

819. «Biberón de barro negro».

816. Pequeña urna miniaturizada de arcilla gris clara.

817. «Campanilla de bronce».

818. Anillo de bronce, sección cuadrangular.

819. Anillo de hueso, sección circular.

\section{Sepultura 2}

820. «Escudilla de barro».

821. Olla de arcilla gris clara, de borde biselado al interior, base cóncava.

(2) Esta relación está basada en los registros e inventarios del Museo de Albacete. Los materiales no localizados son tomados de forma textual y señalados con comillado.
822. Olla de arcilla gris clara, cuello ligeramente marcado, borde biselado al interior, base cóncava.

823. Cuenco de arcilla gris clara, borde ligeramente reentrante, base cóncava.

824. «Botecito».

825. «Tacita con agujeros en el borde».

\section{Sepultura 3}

826. Olla de arcilla gris oscura, borde vuelto al exterior y labio engrosado, doble moldura en el cuello, base restaurada.

827. Cuenco de arcilla gris oscura, borde reentrante, labio plano biselado al interior y fondo plano.

828. Cuenco de borde exvasado y cuerpo de marcado perfil en $\mathrm{S}$, base cóncava. Decoración pintada de bandas y filetes horizontales.

829. «Botecito».

830. Caliciforme de arcilla gris clara, carena media marcada, base cóncava.

831. Jarra de arcilla rojiza, de cuerpo globular y base plana. No conserva el cuello y borde. Presenta el arranque de una única asa.

\section{Sepultura 4}

832. Fragmento de empuñadura de falcata posiblemente con restos adheridos de la vaina.

833. Cinco fragmentos de soliferreum, sección circular.

834. Fragmento de hierro informe.

835. Urna bicónica de cuello estrecho, borde exvasado y labio redondeado, base cóncava. Decoración pintada con un motivo de bandas y filetes horizontales.

836. Plato de arcilla gris oscura, borde exvasado y labio ovalado, ligera inflexión del cuerpo junto al borde, base plana. Presenta agujeros de suspensión.

837. «Fusayola de barro gris».

838. Fíbula de hierro de pie vuelto con botón terminal, puente de sección ovalada, resorte bilateral.

839. Anillo de bronce perteneciente posiblemente a los arreos de un caballo, sección circular.

\section{Sepultura 5}

840. «Falcata de hierro».

841a. Dos fragmentos de punta de lanza de hierro de aletas laterales y nervio central de sección 
circular con abertura para el enmangue parcialmente perdida.

841 b. Regatón de hierro con baquetón en resalte.

842. Fragmento de hierro informe.

843. Fíbula de bronce (no reconstruible).

844. Urna bicónica de arcilla gris oscura, tratamiento espatulado en la superficie externa, borde exvasado acampanado, labio ovalado, base cóncava.

845. «Plato».

846. Fusayola bicónica de arcilla gris, superficie bruñida.

\section{Sepultura 6}

847a. Punta de soliferreum con aletas laterales, sección circular maciza.

$847 \mathrm{~b}$. Regatón de hierro con baquetón en resalte y puntera engrosada.

848a. Bocado de caballo con varilla de sección cuadrangular.

848 b. Bocado de caballo con tres piezas.

849. Fragmento de hierro informe.

850. Fusayola de arcilla rojiza, superficie bruñida.

851. "Fragmento de fíbula».

852. Urna bicónica de arcilla color ocre, borde exvasado y labio redondeado. Decoración pintada con un motivo de bandas y filetes horizontales.

859. "Cinco anillas de bocado de caballo».

910. Fíbula de puente curvo, sección circular, resorte de muelle bilateral. Conserva la aguja.

\section{Sepultura 7}

854. Urna bicónica de arcilla color ocre, borde exvasado y labio triangular, base cóncava. Decoración pintada con motivo de bandas y filetes horizontales.

855. Plato de forma cónica y borde exvasado, base anular. Decoración pintada tanto en el exterior como en el interior. En el interior, grupo de filetes horizontales; en el exterior, un grupo de filetes y bandas enmarcan una banda principal con motivos geométricos cuyo esquema decorativo consiste en la alternancia de semicírculos concéntricos y series de líneas onduladas verticales o «melenas».

856. «Cinco fragmentos de falcata de hierro».

857. Posible fragmento de falcata.

858. Dos fragmentos de empuñadura de falcata.

860. Fragmento de lanza de hierro con aletas laterales y nervio central.
861. Fragmento de hierro informe.

911a. Regatón de hierro.

911 b. Cono de bronce.

\section{Sepultura 8}

853. Fragmento de puente, de sección circular, y pie de fíbula de bronce.

862. «Urna con decoración lineal».

863. Fragmento de plato de barniz rojo de borde exvasado y cuerpo con ligera inflexión. No conserva la base.

864. Fragmento de cuchillo de hierro no dibujable.

865. Fragmento de cuchillo de hierro de hoja recta, sección oval apuntada.

866. Fíbula anular de timbal, resorte de charnela.

867a. Parte de bocado de caballo en bronce con los extremos engrosados.

$867 b$. Fragmento de anillo de fíbula anular con resorte de muelle.

868. Fragmento de hierro informe.

869. Dos fragmentos de cuchillo afalcatado de hierro de sección triangular.

913. Fragmentos de una posible pulsera de bronce, no dibujable.

\section{Sepultura 9}

871. Falcata de hierro con restos de la vaina, sección triangular (no reconstruible).

872. Punta de hierro posiblemente de un soliferreum.

873. Fragmento de soliferreum.

874. Borde de vaso de bronce, borde exvasado y labio engrosado, cuello estrecho, d. $200 \mathrm{~mm}$.

\section{Sepultura 10}

875. Urna bicónica de arcilla gris, borde exvasado y labio apuntado pendiente, base cóncava.

876. Cinco fragmentos de una espada de hierro de sección ovalado con los extremos apuntados. No conserva la empuñadura.

877a. Dos fragmentos de punta de falcata de hierro de sección triangular.

877b. Dos fragmentos de punta de espada o falcata de hierro de sección ovalada apuntada.

877c. Tres fragmentos de punta de espada de hierro de sección ovalada apuntada.

877 d. Dos fragmentos de punta de lanza con aletas laterales y nervio central.

877e. Regatón de hierro; d. máx. $21 \mathrm{~mm}$.; d. int. $12 \mathrm{~mm}$. 
878. Dos fragmentos de soliferreum de sección circular; d: $21 \mathrm{~mm}$.

879. Anillo de hierro de sección triangular d. máx. $40 \mathrm{~mm}$; d int. $18 \mathrm{~mm}$.

880. Plato de casquete hemiesférico de arcilla gris oscura, borde exvasado, labio redondeado, perfil ligeramente en $S$, base plana.

\section{Sepultura 11}

881. Urna bicónica de arcilla rojiza, borde exvasado y labio redondeado, base cóncava.

883. Dos fragmentos de falcata de hierro de sección triangular.

884. «Lanza de hierro».

885a. Fragmento de hierro perteneciente posiblemente al lateral de una vaina de espada.

885b. Fragmento de soliferreum.

886. Triángulo de arcilla gris bruñida. Presenta un orificio ligeramente desplazado del centro de la pieza.

887. Pesa de telar de arcilla rojiza de forma trapezoidal con orificio en la parte superior y una marca en la cara más estrecha.

888. Fragmento de anillo y resorte de una fíbula anular.

889. Botón cónico de bronce con el borde formando a modo de apéndices dispuestos de forma radial.

\section{Sepultura 12}

890. Urna bicónica, borde exvasado y labio de perfil triangular, base cóncava. Decoración pintada con un motivo de grupos de bandas y filetes horizontales.

891. Fragmento de urna como la anterior. Conserva la mitad inferior.

892. Fragmento de fíbula anular de bronce con mortaja, puente de sección circular y resorte de tope osculador.

893. Fragmento de fíbula de bronce que conserva parte del pie y el puente de sección circular con dos finas acanaladuras.

896. «Cuenta de collar de pasta blanca».

91. «As septentario consular romano».

\section{Sepultura 13}

898. Urna bicónica de arcilla gris de la que sólo se conserva la mitad inferior, base cóncava.

899. Fusayola con decoración de puntos incisos.

900. Tapón de arcilla gris clara con una moldura central de perfil anguloso.
901. Dos fragmentos de lanza de hierro de enmangue tubular; d. máx. $22 \mathrm{~mm}$.; d. int. $11 \mathrm{~mm}$.

904a. Bocado de caballo en hierro formado por tres piezas.

904b. Bocado de caballo en hierro formado por dos piezas.

\section{Sepultura 14}

905. Urna bicónica de arcilla rojiza de la que sólo se conserva la mitad superior. Presenta un cuello corto con tres molduras, borde exvasado y labio apuntado. Las asas de sección bilobulada arrancan de la mitad del cono superior y descansan en el mismo borde. Presenta una decoración de grupos de bandas y filetes horizontales; las molduras del cuello y asas se decoran con pequeñas manchas rellenas de color que en el caso de las molduras se disponen de forma ordenada y oblícua.

\section{Sepultura 15}

906. Urna posiblemente bicónica de la que sólo se conserva la mitad inferior, base cóncava de transición a la anular. Presenta una decoración de bandas y filetes que enmarcan dos bandas principales decoradas con series de semicírculos concéntricos.

\section{Sepultura 16}

907. Mitad inferior de una urna posiblemente de cuerpo globular y base anular con una moldura. Presenta decoración pintada muy deteriorada de la que se conserva una serie de semicírculos concéntricos que descansan sobre una banda y enfrentados a esta serie, pero descansando sobre un filete, otra serie de semicírculos concéntricos alternados con grupos de líneas onduladas verticales o «melenas».

908. Urna muy restaurada de arcilla rojiza, de forma bicónica, base cóncava, no conserva el borde. Presenta una decoración pintada de filetes y bandas que enmarcan una banda decorativa principal situada en la mitad superior. El esquema de esta banda se compone de semicírculos concéntricos y series de círculos concéntricos tangentes.

\section{Sepultura 17}

909. Pesa de telar de arcilla rojiza de forma trapezoidal; en la parte superior presenta un orificio de suspensión. 


\section{ESTUdIO CRÍTICO}

Puesto que carecemos de datos estratigráficos, y aún más, las escasas notas sobre las circunstancias de la excavación y los hallazgos son de dudosa interpretación, procederemos al estudio de los enterramientos realizando un análisis formal de los ajuares y obteniendo sus cronologías por medio de paralelos con otras necrópolis de áreas cercanas de la Meseta y del Sureste. Con todo, trataremos de cotejar los resultados del estudio comparativo con las notas manuscritas de F. de Motos, en la medida en que ello sea posible.

\section{Sepultura 1 (Fig. 4)}

De este enterramiento dice su excavador que es romano por tratarse de una inhumación, depositada seguramente en una fosa cavada en el terreno y con una cubrición de piedras planas. En su interior se halló «el esqueleto de un niño y el ajuar», del que sólo se conserva un vaso miniaturizado y dos anillos, uno en bronce y otro en hueso. Sin embargo, F. de Motos añade un nuevo dato: esta sepultura se encuentra entre las ibéricas. Los dos anillos son poco significativos para fijar cronologías, pero si observamos el perfil del pequeño vaso recuerda claramente un momento ibérico pleno. La existencia de vasos que reproducen en pequeña escala formas usuales del ajuar cerámico se conoce desde la Edad del Bronce, apareciendo incluso en lugares de hábitat. Sin embargo, es desde época ibérica cuando el

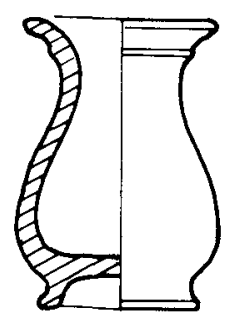

816
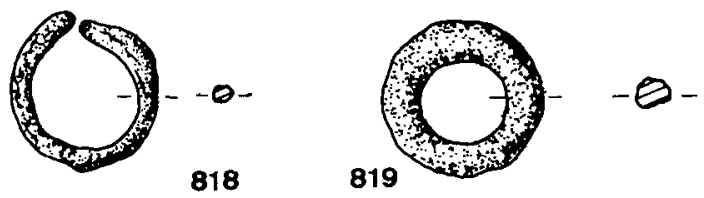

Fig. 4.- Sepultura 1. hallazgo de estos vasos se hace más frecuente, siendo curiosamente más abundante en contextos de necrópolis. Véase por ejemplo la Sepultura 70 de Coimbra (INIESTA ET ALII, 1987, fig. 12) en cuyo ajuar aparecieron varios de estos vasos pero en esta ocasión hechos en madera. En este sentido, y sin intención de establecer paralelos, conviene mencionar que esta costumbre de fabricar vasos miniaturizados, que copian fielmente los modelos en todos sus detalles, está muy enraizada en el mundo púnico en momentos también plenos. En los fondos del Museo de Cártago se pueden ver imitaciones de este tipo, incluso en la técnica del barniz negro.

Por otro lado, en la última campaña del Tolmo de Minateda apareció un vaso idéntico a éste, en el sector de la necrópolis norte en proceso de excavación. Se encontró en un estrato de relleno cuyos materiales no bajaban del s. II a. C. En último extremo, no sobrepasaría el s. I d. C. puesto que es la fecha más tardía que ha dado la secuencia de este sector.

Dejando aparte la cuestión de si se trata de vasos de juguete o de carácter ritual, este paralelo de la necrópolis norte permite adscribir el enterramiento a un momento ibérico, aunque por ahora no se pueda concretar si es de época plena o más tardía.

Por otro lado, el anillo de bronce número 818 realizado con un alambre de sección cuadrangular, no tiene claros paralelos entre las inhumaciones conocidas de época romana. Lo mismo ocurre con el anillo de hueso número 819 .

\section{Sepultura 2 (Fig. 5)}

De este enterramiento dice de Motos que es también "romano por inhumación», siendo la tumba de fosa cavada en el terreno y con un enlucido de «barro amasado con paja». Del ajuar sólo se conserva un cuenco y dos ollas de pasta gris con una calidad más grosera que la de las grises ibéricas. El cuenco (número inv. 823) es idéntico al aparecido en la tumba 223 de la Hoya de Santa Ana, pero lamentablemente sin otro elemento que permita fecharlo. Por otro lado, las dos ollas que corresponden a la misma producción cerámica que el cuenco anterior, están bien fechadas en la necrópolis norte del Tolmo, actualmente en excavación, habiendo aparecido como urnas conteniendo incineraciones en un nivel alto-imperial del s. I d. C. 


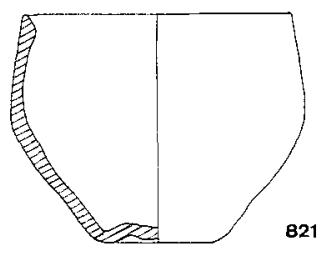

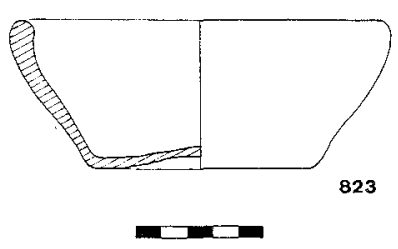

Fig. 5.- Sepultura 2.

Sepultura 3 (Fig. 6)

F. de Motos compara este enterramiento con los anteriores por contener «un esqueleto y el ajuar...». Sin embargo, en el ajuar es obligado hacer una doble distinción: por un lado, el cuenco número 827 y la jarra número 831 que se caracterizan ambos por estar fabricados en una pasta de calidad más bien grosera; y por otro, los vasos número 826 , 828 y 830 .

El cuenco número 828 es una forma muy frecuente que tiene su inicio en los s. VI y V, aunque su máxima dispersión se produce en el s. IV a. C. (PEREIRA, 1988, Variante 5AII, fig. 7). En efecto, la encontramos en contextos de esta cronología en poblados de Murcia como Ascoy y Molinicos (LILLO, 1981, ASC. VI, 1 Y MOL. XVI, 4); en el País Valenciano se halla tanto en poblados como necrópolis: en la Escuera aparece en el Dep. F con fecha del s. III a. C. (NORDSTRÖM, 1967, fig. 31); lo tenemos también en la necrópolis de La Albufereta (RUBIO, 1986, fig. 19); en Los Villares (PLA, 1980, LÁM. XI, 3).

En toda la zona del Alto Guadalquivir se halla ampliamente representada (PEREIRA, 1988, 155) e incluso en la necrópolis de la Bobadilla, con una tendencia más achatada (MALUQUER ET ALII, 1973, Sep. 12). En yacimientos cercanos al Tolmo lo encontramos en los Villares (Tumba 43, Fase II de la necrópolis) y en la Tumba 22 de la Hoya de Santa Ana.

El caliciforme número 830 de nuevo lo encontramos en poblados de Murcia como el Cabezo de la Cerámica, Ascoy (LILLO, 1981), Coimbra (MO-
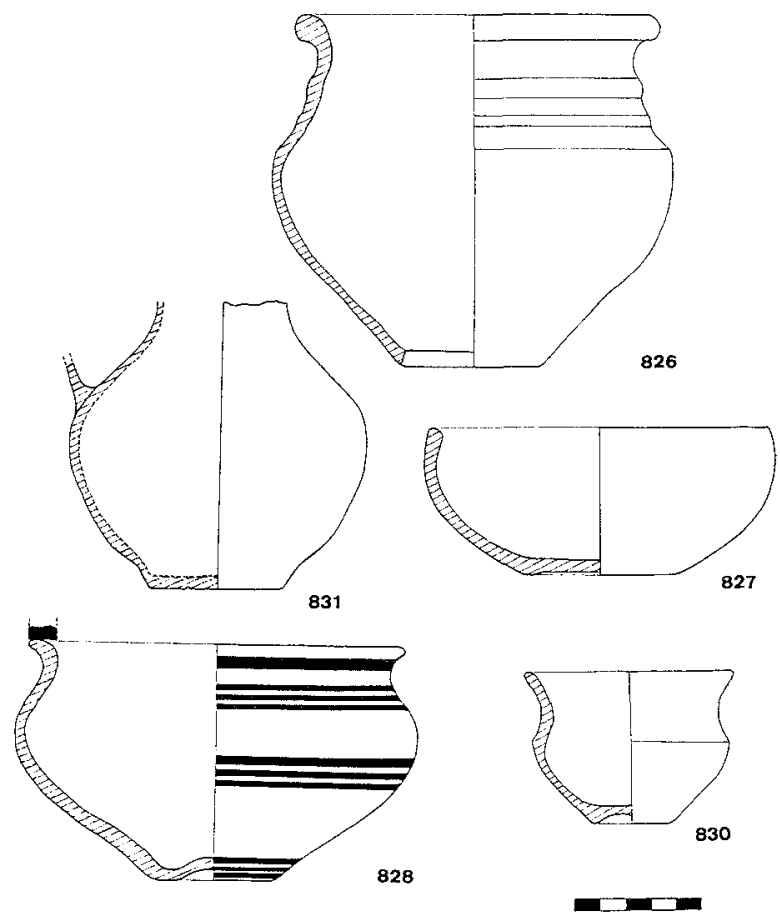

Fig. 6.- Sepultura 3.

LINA Y NORDSTRÖM, 1976, fig. 18), aunque es en el poblado de la Bastida donde podemos concretar su cronología en pleno s. IV a. C. al aparecer en el Dep. 37 junto a una crátera ática Lamb. 40 y un oenochoe Lamb. 44 (FLETCHER ET ALII, 1965, 183).

La urna de pasta gris número 826 posee una cronología similar al vaso anterior puesto que podemos fecharla por su asociación a cerámica de barniz negro ático de la forma Lamb. 21/25 en el Dep. 91 de la Bastida (FLETCHER ET ALII, 1969, 232). En Coimbra la encontramos tanto en pastas grises como en claras, aunque aquí sólo se pueden fechar dentro del margen cronológico del poblado, s. IVIII a. C. (MOLINA Y NORDSTRÖM, 1976, Lám. XII). Donde es realmente abundante es en El Amarejo, fechándose aquí en el s. III a. C. (BRONCANO Y BLÁNQUEZ, 1985, fig. 23, 47, 48, 76 у 77).

Tenemos un grupo de vasos que podemos encontrar desde el s. IV al III a. C., siempre en yacimientos con un contexto de época clásica, mientras que el cuenco número 827 muy similar al de la Sep. 2 e idéntico a otros aparecidos en la excavación de este año en la necrópolis norte, se puede fechar en el s. I d. C. La jarra es difícil de clasificar con los elemen- 
tos formales que conserva; no obstante, la pasta con desgrasantes de gran tamaño es de calidad bastante grosera, con seguridad no ibérica, y permitiría fecharla a partir de época altoimperial. Por lo tanto, creemos que en la Sep. 3 hay en realidad dos enterramientos mezclados, a juzgar por las cronologías de los ajuares, uno del s. IV-III a. C. y otro del s. I d. C.

\section{Sepultura 4 (Fig. 7)}

Se trata de un típico enterramiento de incineración ibérico, y así parece confirmarlo la coherencia del ajuar. La urna número 835 contenía los restos de la incineración y el plato serviría seguramente, aunque no hay mención expresa, de tapadera de la urna. Este tipo de urnas no es muy frecuente, si bien podemos encontrar vasos comparables a éste, con cuello incipiente y hombro, en Molinicos (Murcia) (LILLO, 1981, MOL. XXII, 7) poblado cuya cronología abarca desde el s. VI a la primera mitad del s. IV a. C., o en la necrópolis de Baza (PRESEDO, 1982, fig. 125 y 126) en el s. IV a. C.

En cuanto al plato-tapadera, se trata de una forma bastante extendida que podría tener sus antecedentes en los platos polícromos de Setefilla (AUBET, 1976, fig. 1 y 7) o en los platos grises a torno con superficies bruñidas que aparecen en el s. VI a. C. en Librilla (Murcia) (ROS SALA, 1989, tipos IIIG5, 251, IIIG10 y IIIG11, 254). En el s. V a. C. encontramos estos mismos platos pero en pasta gris, sin policromía, en la tumba 7 de Los Villares y en el poblado de El Oral (3). También aparecen en la cercana necrópolis del Tesorico, si bien aquí son materiales sin contexto (BRONCANO ET ALII, 1985, fig. 47).

(3) La Memoria de las excavaciones en el poblado ibérico de El Oral (San Fulgencio, Alicante) se halla en curso de realización. No obstante, hay publicados algunas noticias generales sobre el yacimiento y un avance de la urbanística. Véase ABAD CASAL, L.: «El Oral» en Arqueología en Alicante, 1976-1986. Alicante, 1986, pp. 143-145; «El poblamiento ibérico en la provincia de Alicante» en Iberos. Actas de las $I$ Jornadas sobre el Mundo Ibérico. Jaén, 1985 (Jaén, 1987), pp. 157-169; «Algunas reflexiones en torno a hábitats, poblados y estructuras domésticas de época ibérica en el sur del Pais Valenciano» en Colloque International Habitats et structures doméstiques en Méditerranée Occidental durant la Protohistoire, Arlés, 1989 (en prensa).
La fíbula número 838 , perteneciente al grupo de pie vuelto con botón terminal, presenta unas medidas que la hacen única en su tipo. No encontramos paralelos exactos a excepción de un ejemplar similar localizado en la necrópolis de La Solivella (Alcalá de Chivert, Castellón), formando parte del ajuar de la sepultura 14, asociada a un broche de cinturón de tres garfios y a una urna de orejetas (FLETCHER, 1965, lám. 27). El resorte, mal conservado, sería bilateral y posiblemente largo, con el muelle arrollado a ambos lados en torno a un eje del mismo material; conserva el arranque de la aguja. El puente, curvo aplanado, tiene una sección circular bastante gruesa. El pie, rematado en el característico botón de tipo bola, tiene tendencia a la horizontalidad, y no conserva restos de la mortaja.

La cronología que damos a esta fíbula está en torno al final del s. VI a. C. y la mitad del s. V a. C., sin descartar un mantenimiento de este tipo a lo largo de la segunda mitad de este último siglo, coicidiendo así con las estimaciones aportadas por Cuadrado (CUADRADO, 1963).

El fragmento superior de un soliferreum no aporta datos cronológicos concretos. En la necrópolis de El Cigarralejo (Mula, Murcia) (CUADRADO, 1989, fig. 65 y 66) se fechan a fines del s. V y primera mitad del s. IV a. C. Otro caso similar ocurre en la necrópolis de El Tesorico (AgramónHellín, Albacete) (BRONCANO ET ALII, 1985, 102 y 103), en donde se fecha a mediados del s. IV a. C. por los materiales de importación áticos. También es cierto que perduran durante bastante tiempo, por lo que no son fiables como elemento de datación.

Otra de las piezas metálicas conservadas es la empuñadura fragmentada de una falcata, número 832, que lleva adherido un trozo de la contera. La amplia dispersión cronológica y espacial de este tipo de arma ofensiva ha sido puesta de manifiesto acertadamente por los investigadores de la necrópolis de El Tesorico (BRONCANO ET ALII, 1985). Su presencia en necrópolis del área de Granada, como el Mirador de Rolando (ARRIBAS, 1967) o Baza (PRESEDO, 1982), señalan el límite de dispersión de estas piezas hacia el suroeste, conjuntamente con las aparecidas en la necrópolis de Los Collados (Almedinilla, Córdoba) (SCHÜLE, 1969, Láms. 73 a 77). Por otra parte, tenemos atestiguado su uso en Jaen, localizadas en las necrópolis de Cástulo (BLÁZQUEZ, 1975), así como en la de la «Finca Gil de Olid» (RUIZ RODRÍGUEZ ET ALII, 1984). 

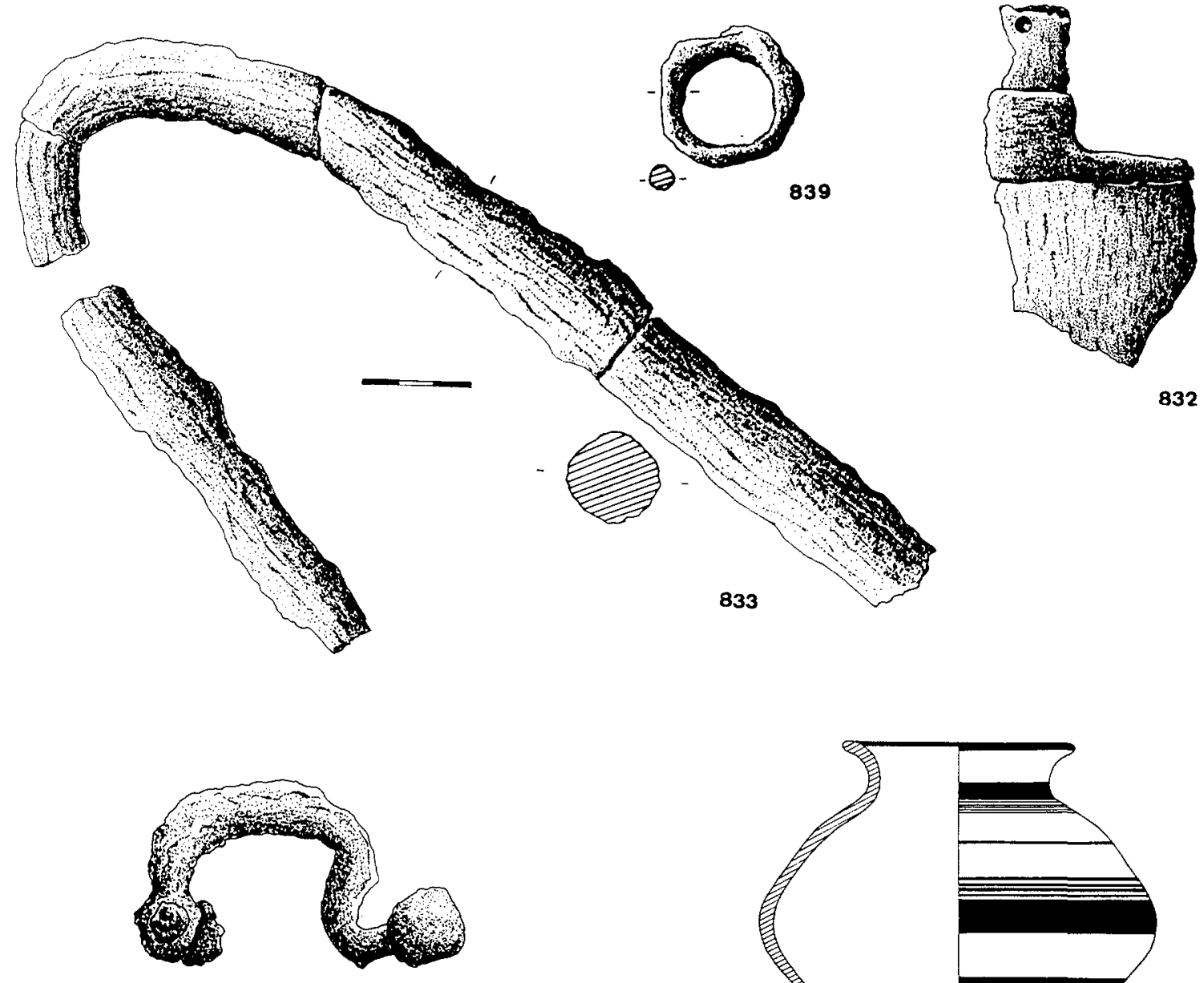

838
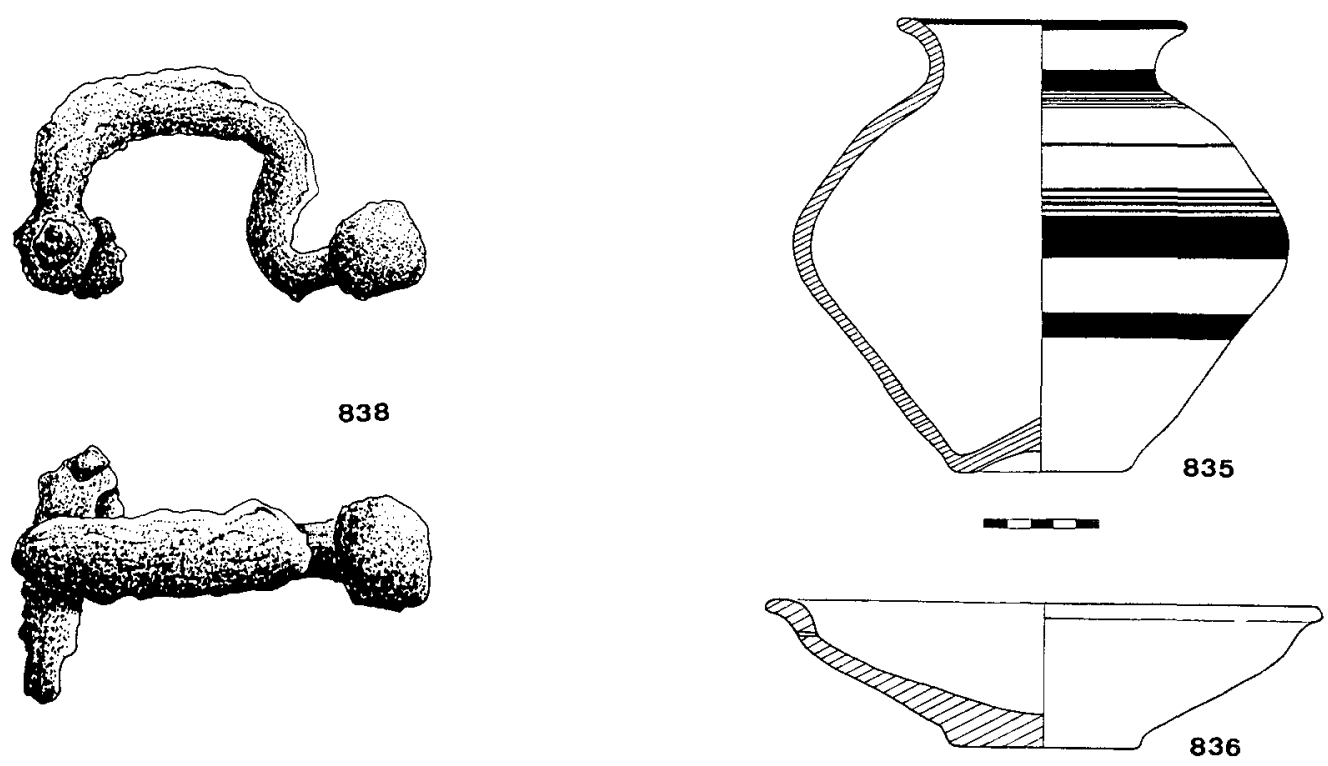

Fig. 7.- Sepultura 4.

En la provincia de Almería no tenemos constancia de su presencia en necrópolis contemporáneas a la nuestra, mientras que en Murcia se localizan bastantes ejemplares: Cabecico del Tesoro (NIETO, 1947), Cabezo del Tío Pío (SAN VALERO y FLETCHER, 1947), en las sepulturas 27 y 30 de Los Nietos (CRUZ PÉREZ, 1988), y sobre todo en El Ci- garralejo, donde ha dado pie a un estudio tecnológico preciso (CUADRADO, 1989). La cronología de este tipo de armas parece oscilar entre el s. V a. C. y la plena romanización del territorio hispano, lo cual confirmaría su operatividad durante mucho tiempo como arma principal en el combate cuerpo a cuerpo. 


\section{Sepultura 5 (Fig. 8)}

Hallada como la anterior «...entre cenizas y carbones...» corresponde a un enterramiento de incineración ibérico. La urna posee unas características formales y técnicas muy peculiares. Está fabricada en una pasta gris, bastante bien depurada, a torno, y con un tratamiento exterior espatulado. Los trazos del espatulado siguen direcciones distintas (horizontales y verticales) según sea el cono inferior o el superior, intentando dar una finalidad decorativa posiblemente. Este tratamiento tan frecuente en la cerámica a mano, no lo es tanto cuando se trata de producciones a torno. Podemos citar los ejemplos de los platos grises de Librilla (Murcia) (ROS SALA, 1989) que se sitúan claramente en el s. VI a. C., y quizá algo más recientes y más interesantes en cuanto a la relación geográfica con El Tolmo de Minateda, los cuencos-tapaderas de la necrópolis del Peñón del Rey (Villena, Alicante) (HERNÁNDEZ ALCARAZ, 1990).

El perfil bicónico con cuello y borde acampanado es también un rasgo distintivo. Aunque con menor fidelidad, creemos que estos vasos responden a una recreación indígena de los vasos «achardonados», muy concreta de esta parte de la provincia de Albacete. Los vasos achardonados son muy frecuentes en los poblados murcianos, pero casi todos son de pastas ocres y con decoración geométrica pintada más acorde con los prototipos. Los encontramos en Molinicos, Ascoy, Castillico de las Peñas, y más al norte, en la necrópolis de $\mathrm{La}$ Albufereta. Sin embargo, los paralelos exactos se hallan en la necrópolis del Camino de la Cruz fechada en el primer cuarto del s. V a. C. (BLÁNQUEZ, 1984, 187 y 194), en Los Villares, en tumbas de las fases I y II, abarcando por ello todo el s. V, y en las tumbas 32, 67 y 146 de la Hoya de Santa Ana (BLÁNQUEZ, 1990, Fig. 42). En cambio, están ausentes en la necrópolis del Tesorico cuya cronología inicial es del s. IV a. C.

El fragmento de punta de lanza número 841a se podría englobar en el tipo 1 ó 2 de Cuadrado (CUADRADO, 1989, 57), que se fechan entre el último cuarto del s. V y todo el s. IV a. C.

El objeto número $841 \mathrm{~b}$ es probable que se trate del enmangue tubular de la mencionada lanza. La anilla que presenta daría más solidez a la unión, si bien cabría la posibilidad de que fuera parte de un regatón cuya tendencia cónica no parece reflejarse en esta pieza.

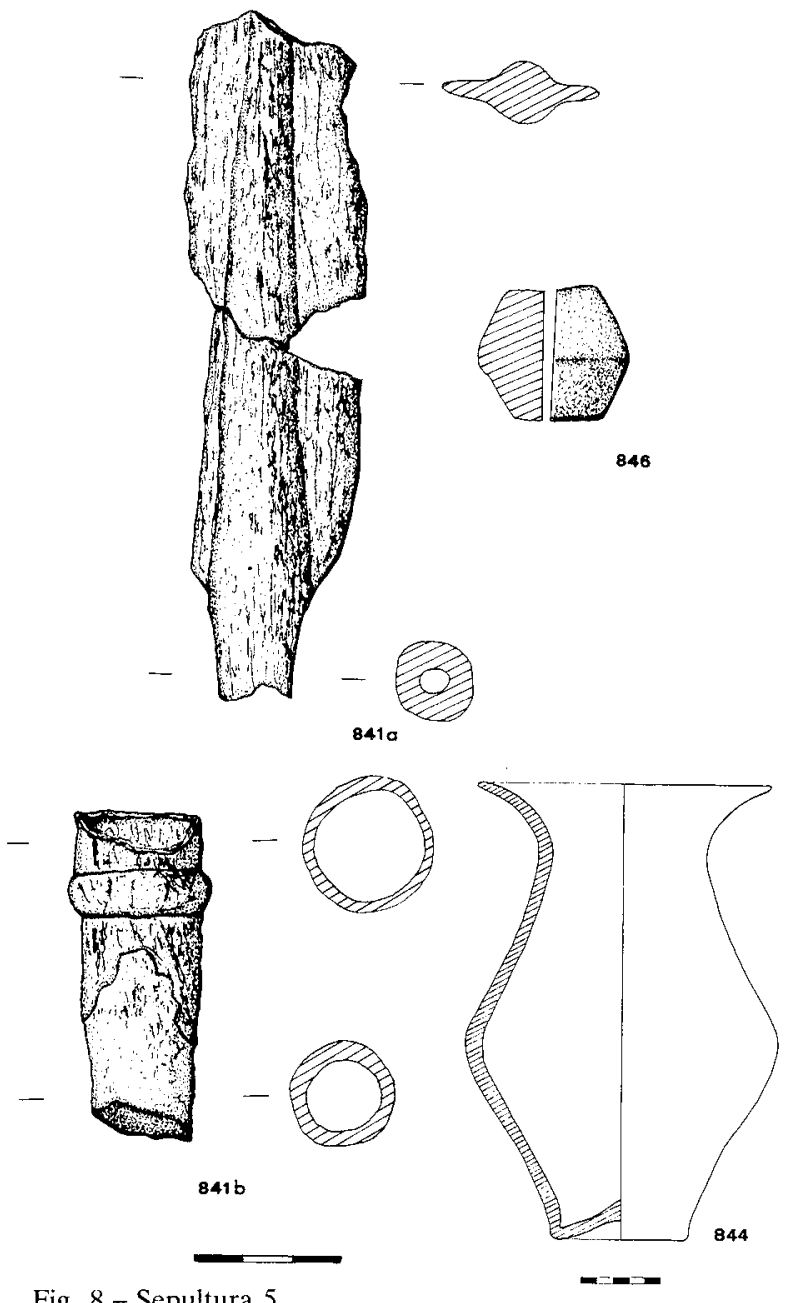

Fig. 8.- Sepultura 5.

Queda señalar, por último, una fusayola bitroncocónica con la superficie de color gris bruñida.

\section{Sepultura 6 (Fig. 9)}

De esta sepultura no se señala característica alguna sobre el enterramiento; sí en cambio, la posición del ajuar: fuera de la urna, la lanza y los bocados de caballo, y dentro de ella, la fíbula y la fusayola.

Este tipo de vasos, bicónicos con decoración pintada a base de grupos de bandas y filetes, es el prototipo de urna cineraria de un conjunto de necrópolis cuya cronología se incluye dentro del s. V a. C. Se trata de una forma que está ya documentada en el s. VI a. C. tanto en el Rosellón francés como en la Península Ibérica, y al parecer sus perfiles permanecen con pocas variaciones hasta lle- 

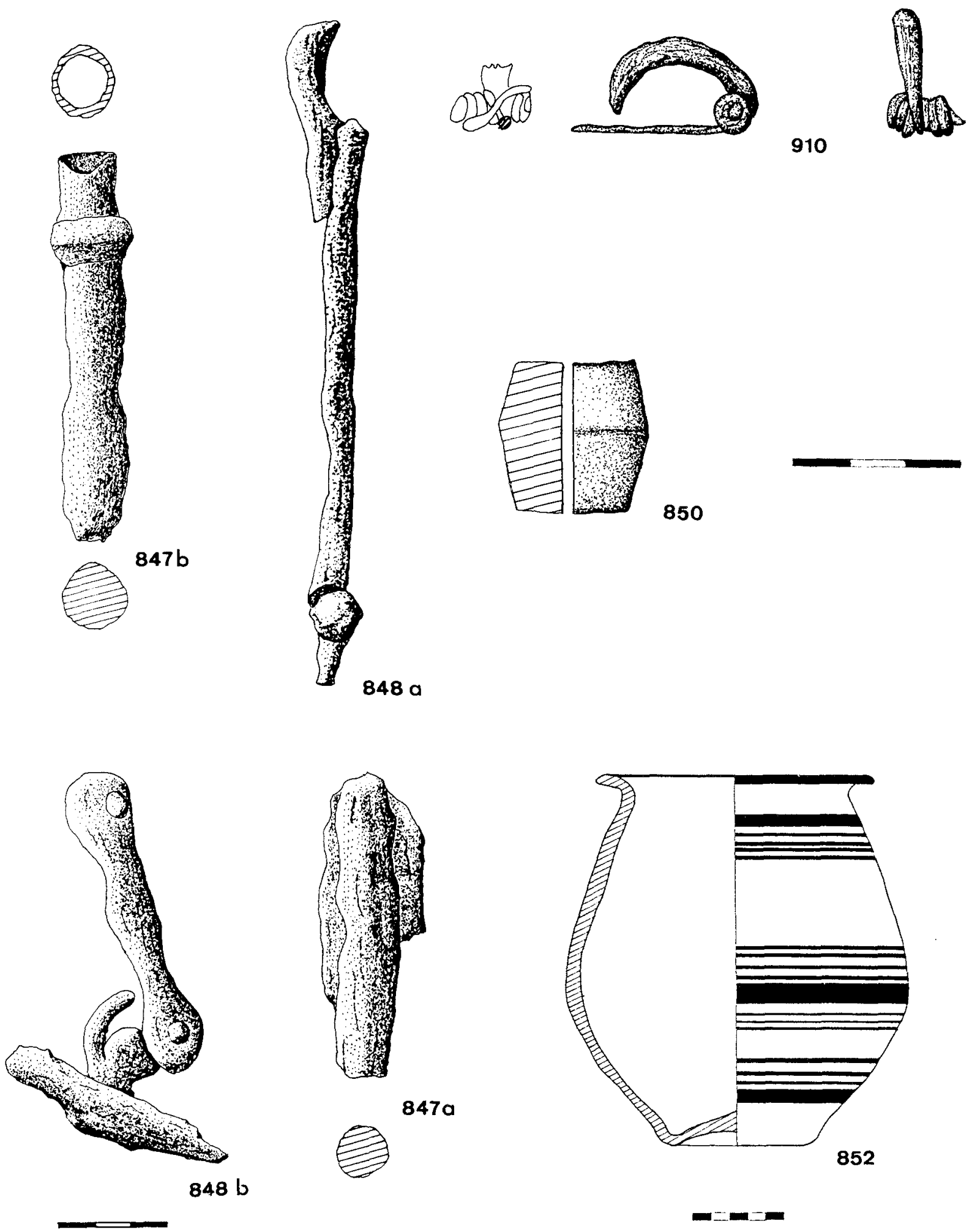

Fig. 9.- Sepultura 6. 
gar al s. IV a. C. donde adoptan una forma más esférica y panzuda (JULLY y NORDSTRÖM, 1972, 4 y 5; PEREIRA, 1988, 148).

Sin entrar en la discusión sobre su origen, y sobre los distintos tipos establecidos de esta forma, tipos A, B, C, C' y D (JULLY Y NORDSTRÖM, 1972), creemos que lo realmente interesante para el estudio de esta necrópolis del Tolmo es señalar su presencia como elemento funerario en otras necrópolis con la misma cronología y características que la que nos ocupa. La encontramos en La Solivella (Castellón) (FLETCHER, 1965), El Molar (4) (SENENT, 1930), y en los yacimientos de Molinicos (LILLO, 1981, MOL. XXI, 3) y El Monastil (Elda, Alicante) (POVEDA, 1988, fig. 16), aunque en ambos se presenta lamentablemente fuera de contexto arqueológico.

Mucho más significativa es su presencia como prototipo de urna cineraria en necrópolis cercanas como la del Camino de la Cruz y Los Villares en Hoya Gonzalo (BLÁNQUEZ, 1984, Lám. III, VII y VIII), también encuadradas dentro de este mismo siglo.

La fíbula número 910 se puede asociar al grupo de las anulares, perteneciendo al tipo 4 de Cuadrado, de navecilla (CUADRADO, 1957, 312 y ss.), o bien al 9 (CUADRADO, 1957, 317 y ss.), sin poder establecer la variante correspondiente debido a la pérdida del pie y apéndice caudal. Esta indefinición nos obliga a establecer una cronología global para nuestra pieza entre fines del s. V a.C. y todo el s. IV a.C.

La punta de soliferreum número 847 a se puede englobar entre el último cuarto del $\mathrm{s}$. $\mathrm{V}$ y todo el s. IV a. C. (CUADRADO, 1989, 65 y 66).

El mal estado de conservación de la pieza número 847 b no nos permite fijar su agrupación tipológica, aunque es probable que se trate de una punta de lanza o jabalina, que en cualquier caso debe situarse a fines del s. V y todo el s. IV a. C.

(4) Sobre esta necrópolis existe una tesis de licenciatura presentada por M. Monraval el año 1985 en la Universidad de Valencia, con el título «La necrópolis ibérica de El Molar (San Fulgencio-Guardamar del Segura, Alicante)». (Inédita). Véase también MONRAVAL, M. y LÓPEZ, M.: «Restos de un silicernio en la necrópolis ibérica de El Molar». Saguntum, 18, 1984, pp. 145-162; PADRO, J.: «Los objetos de tipo egipcio de la necrópolis del Molar (San Fulgencio, Alicante) y su problemática». CPAC, 2, 1975, pp. 133-142.
Las piezas número 848 a y $\mathrm{b}$ corresponden a los arreos de un bocado de caballo.

La fusayola, también de cuerpo bitroncocónico, posee una calidad de acabado similar a la que se encontró en la Sepultura número 5.

Por lo tanto, el ajuar metálico permite acercar la cronología de este enterramiento a fines del s. V a. C.

\section{Sepultura 7 (Fig. 10)}

De este enterramiento no se señala más información que la relación del ajuar aparecido fuera de la urna. El ajuar metálico conservado es poco destacable, y por lo que respecta al cerámico se plantea un problema ante la asociación de la urna con el plato. Esta urna número 854 , junto a un vaso de La Alcudia de Elche y otro de Toya, son los ejemplos citados por Jully y Nordström como urnas bicónicas del tipo B fechadas en el s. IV a. C. (JULLY y NORDSTRÖM, 1972, 96, PL. VIII). Sin embargo, en este trabajo se señala la presencia del mismo tipo en La Solivella y El Molar, necrópolis cuya cronología no baja del s. V a. C. Si además notamos el paralelismo en todos los aspectos con la urna de la sepultura anterior, podemos asegurar una cronología del s. V a. C. para esta misma. Por otro lado, es muy similar a la variante 6AI de Pereira, cuyos ejemplares más antiguos en la cuenca del Alto Guadalquivir se fechan también en el s. V. a. C. (PEREIRA, 1988, 155-157).

En cuanto al plato, por su forma y decoración, pertenece a un tipo muy extendido en poblados y necrópolis de los s. IV-III a. C., es decir, a un momento ibérico pleno. Lo encontramos en El Amarejo, La Escuera y Puntal dels Llops en Departamentos fechados en el s. III a. C. (BRONCANO y BLÁNQUEZ, 1985, fig. 85 a 91; NORDSTRÖM, 1967, fig. 16d; BONET y MATA, 1981, fig. 44 y 52); en la Sepultura 70 de Coimbra aparece bien fechado a principios de la segunda mitad del s. IV a. C. (INIESTA ET ALII, 1987, fig. 5, 6, 7 y 8). Aparece en el Tesorico, donde a pesar de ser hallazgos de superficie, se pueden fechar a partir del s. IV a. C. Con esta misma cronología se halla ampliamente representado en la necrópolis del Cigarralejo (CUADRADO, 1987).

El enmangue de falcata número 858 , posiblemente del tipo cabeza de pseudocaballo (CUADRA- 


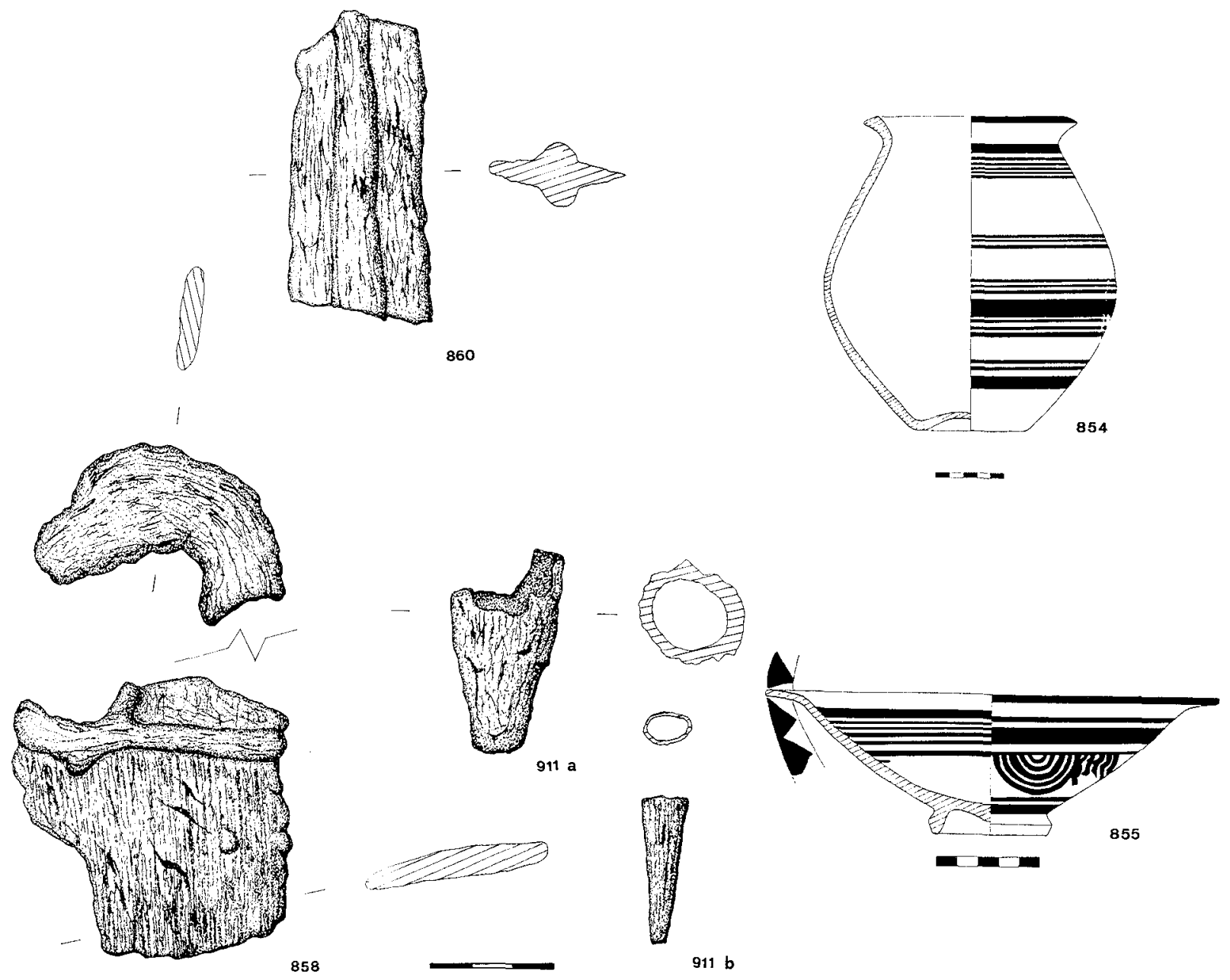

Fig. 10.- Sepultura 7 .

DO, 1989, 21), presenta restos de la guarda basal en el inicio de la hoja. Para la cronología general nos remitimos a lo ya expuesto para la pieza de la Sepultura 4.

Las piezas número 911 a y 860 corresponden respectivamente a un regatón bastante degradado y a un fragmento de punta de lanza con nervio central. Ambas deben pertenecer a la misma arma. La cronología estimada coincide con lo especificado para otros objetos similares.

Por último, señalar la presencia de un cono de bronce formado por una lámina enrrollada, número $911 \mathrm{~b}$, del que encontramos una pieza muy parecida en la tumba número 3 de la necrópolis de $\mathrm{El}$ Tesorico (BRONCANO ET ALII, 1985, 70, fig. 17).
Sepultura 8 (Fig. 11)

Tampoco contamos para este enterramiento con mayor información que la situación del ajuar metálico dentro o fuera de la urna, sin ningún otro dato acerca del tipo de tumba.

Aunque la urna no ha podido ser localizada, tenemos dos elementos que permiten fechar con cierta seguridad esta sepultura. El primero es un fragmento de borde de una pátera de barniz rojo, que según la clasificación de Cuadrado correspondería al tipo 1. Platos idénticos a éste aparecen en varias tumbas del Cigarralejo asociadas a cerámica ática de barniz negro que les otorgan una cronología del s. IV a. C., válida también para esta sepultura 8 

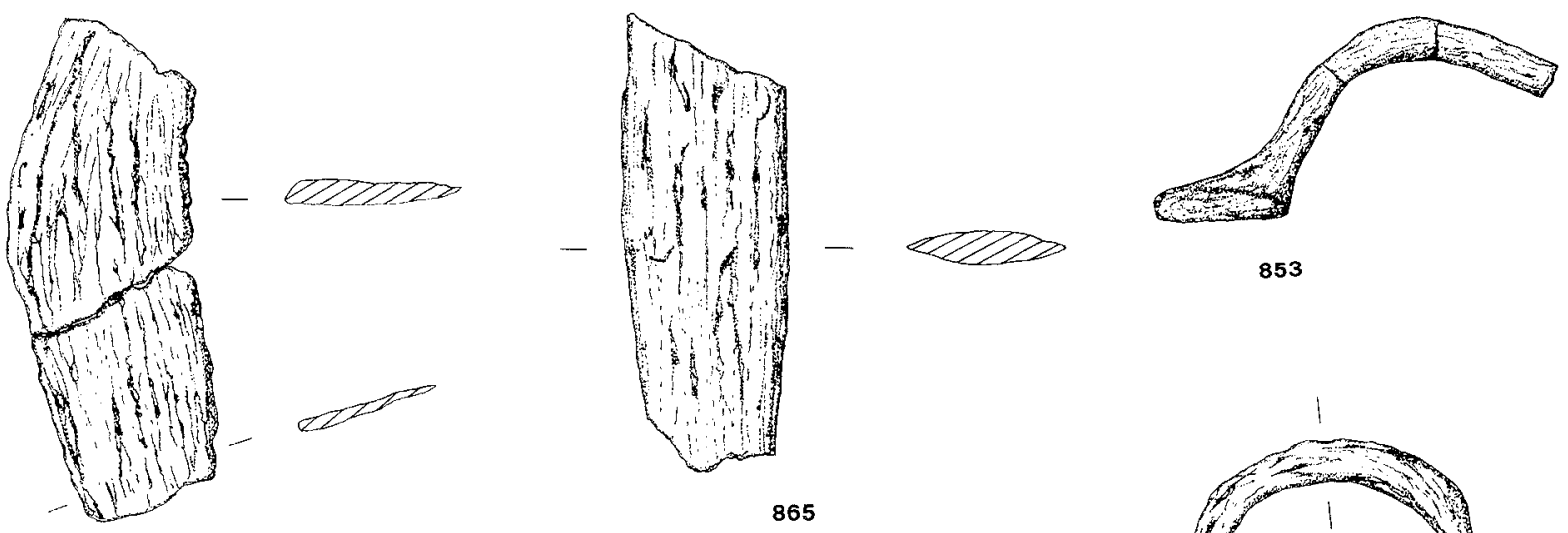

869

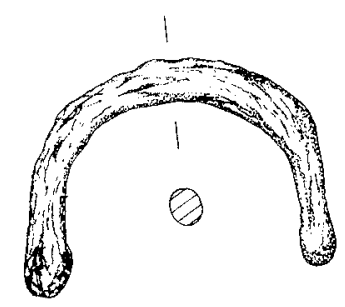

867
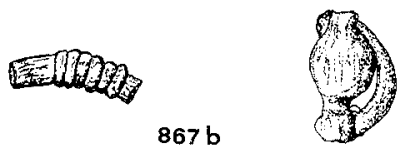

866

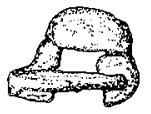

Fig. 11.- Sepultura 8.

(CUADRADO, 1987, 81, fig. 54, 177 y 206). En la tumba 5 de Baza aparece un plato de barniz rojo de esta forma junto a un plato similar al de la Sepultura 7, lo cual vendría a corroborar la sincronía de estos materiales (PRESEDO, 1982, fig. 5).

El segundo es la fíbula anular de timbal hemiesférico con resorte de charnela (número 866). Esta pieza corresponde al tipo $2 \mathrm{e}$ variante II de la clasificación de Cuadrado (CUADRADO, 1957, 15). La propuesta de Iniesta para las fíbulas anulares de Murcia encuadra ejemplares similares al nuestro entre el final del s. V y la mitad del s. IV a. C., siendo éstos los límites en los que podemos fechar la sepultura en estudio (INIESTA, 1983, 252).

El fragmento de anillo con muelle enrrollado de fíbula anular número $867 \mathrm{~b}$ podría paralelizarse, con las naturales reservas debido al pequeño tamaño de lo conservado, con el tipo 4 ó 9 de Cuadrado. Otro fragmento de fíbula, esta vez parte del puente y la mortaja completa (número 853), no aporta datos que concreten la cronología.
Completan el ajuar metálico dos fragmentos de cuchillos de hierro, el primero, de forma afalcatada, con sección triangular (número 869), y el segundo, de perfil recto, sección ovalada y extremos afilados (865), aunque este último bien podría tratarse de la parte medial de una punta de lanza como la encontrada en Quintanar de Gormaz (Soria) (SCHÜLE, 1969, lám. 32, 3). En el caso del cuchillo afalcatado se puede rastrear su origen y procedencia si nos fijamos en los ajuares de Setefilla (AUBET, 1975) que se fechan globalmente entre los s. VII y VI a. C. Hacia el oeste, en función de la vía de comunicación establecida por el Tajo, se han encontrado ejemplares en Alcácer do Sal, en Portugal (SCHÜLE, 1969, lám. 92 y 105), donde se fechan desde fines del s. VII a. C. hasta la romanización. Este dato se confirma con las piezas encontradas en la necrópolis de Medellín, en los conjuntos número 12 y 19 (ALMAGRO GORBEA, 1977, 307, 309 y 322), fechadas a mediados del s. VI a. C. y en su segunda mitad. Otra necrópolis de reciente pu- 
blicación, esta vez en Cáceres, conocida como Castillejo de la Orden (ESTEBAN ORTEGA ET ALII, 1988 ) ofrece cuchillos afalcatados en la práctica totalidad de sus sepulturas.

En el interior meseteño se conocen ejemplares en el Altillo de Cerropozo (Atienza, Guadalajara) (SCHÜLE, 1969, lám. 13, 15, 17, 18 y 20); en Quintanar de Gormaz (Soria) (Ibídem: lám. 32); La Mercadera (Soria) (Ibídem: lám. 49); en Osma (Soria) (Ibídem: lám. 55); Las Cogotas (Ávila) (Ibídem: lám. 117), o en Miraveche (Burgos) (Ibídem: lám. 144). La cronología estimada por Schüle para la Meseta oscila entre fines del s. VI a. C. hasta la romanización, con lo que se demuestra asimismo su validez como instrumento de guerra, asociado a la falcata en cuya vaina iría sujeto por fuera, sin olvidar su uso como útil doméstico.

También aparece un ejemplar de relativa antigüedad en la necrópolis de Sigüenza (CERDEÑO SERRANO, 1981, 195) en la sepultura 1, fechada en el s. VI a. C. En la provincia de Cuenca se tiene constancia de una pieza en la tumba 11 de la necrópolis de Las Madrigueras (Carrascosa del Campo) (ALMAGRO GORBEA, 1969, 47 y ss.).

En la provincia de Murcia existe un ejemplar en Los Nietos (Cartagena) (CRUZ PÉREZ, 1988, 204), en la tumba 27, fechada entre el 375 y el 350 a. C. por la cerámica de barniz negro asociada. Otro yacimiento que presenta cuchillos de hoja curva es El Cigarralejo, donde su excavador diferencia 5 tipos (CUADRADO, 1989, 75 y 76). Nuestro ejemplar equivaldría al tipo 2 ó 2 bis con una cronología amplia, primera mitad del s. IV a. C. hasta el s. II a. C.

Ya dentro de la provincia de Albacete tenemos otra pieza en la tumba 3 de la necrópolis de $\mathrm{El} \mathrm{Te}$ sorico (BRONCANO ET ALII, 1985, 67 y ss.), en la primera mitad del s. IV a. C. En la necrópolis de Casa del Monte (Valdeganga) también aparecieron exclusivamente cuchillos de hoja curva (BALLESTER TORMO, 1939, 46).

La pieza número 867 pertenece probablemente a los arreos de un bocado de caballo.

\section{Sepultura 9 (Fig. 12)}

En esta sepultura aparecen un fragmento de soliferreum, número 873 , y una punta de lanza o jabalina corta con aletas laterales, número 872 , que
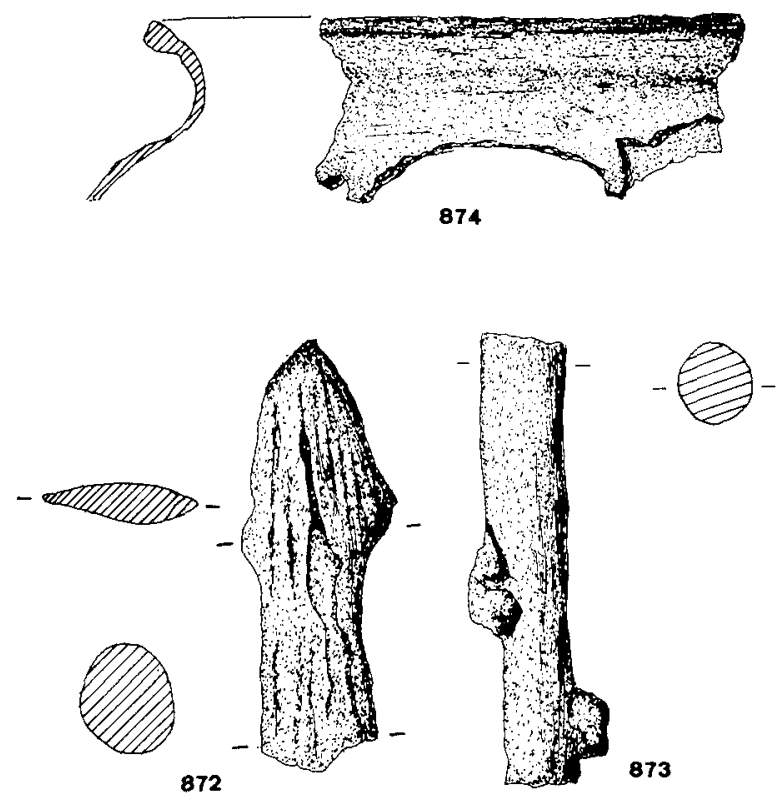

Fig. 12.- Sepultura 9.

forman el conjunto de armas de este enterramiento, y que no aportan datos para definir la cronología.

El borde de un vaso de bronce, que podría haber servido de urna, número 874 , se encuentra tan fragmentado que no permite reconstruir un perfil fiable. Por su diámetro y hombro debe corresponder a una forma cerrada, descartando por estas mismas razones la posibilidad de que se tratase de un brasero o un oenochoe.

Sepultura 10 (Fig. 13 y 14)

De esta sepultura no se especifica dato alguno sobre el sistema de enterramiento o la posición del ajuar. Se conserva la urna, un plato de la misma arcilla que seguramente constituiría la tapadera de ésta y numerosos objetos metálicos.

La urna de cuerpo bicónico presenta una forma bastante común difícil de datar sin otro elemento formal más significativo. Sin embargo, la presencia de urnas similares a ésta en forma y calidad de pasta en las tumbas 39 y 24 de Los Villares (fase I y II respectivamente) permiten fecharla en el s. V a. C. Además concuerda perfectamente con el 

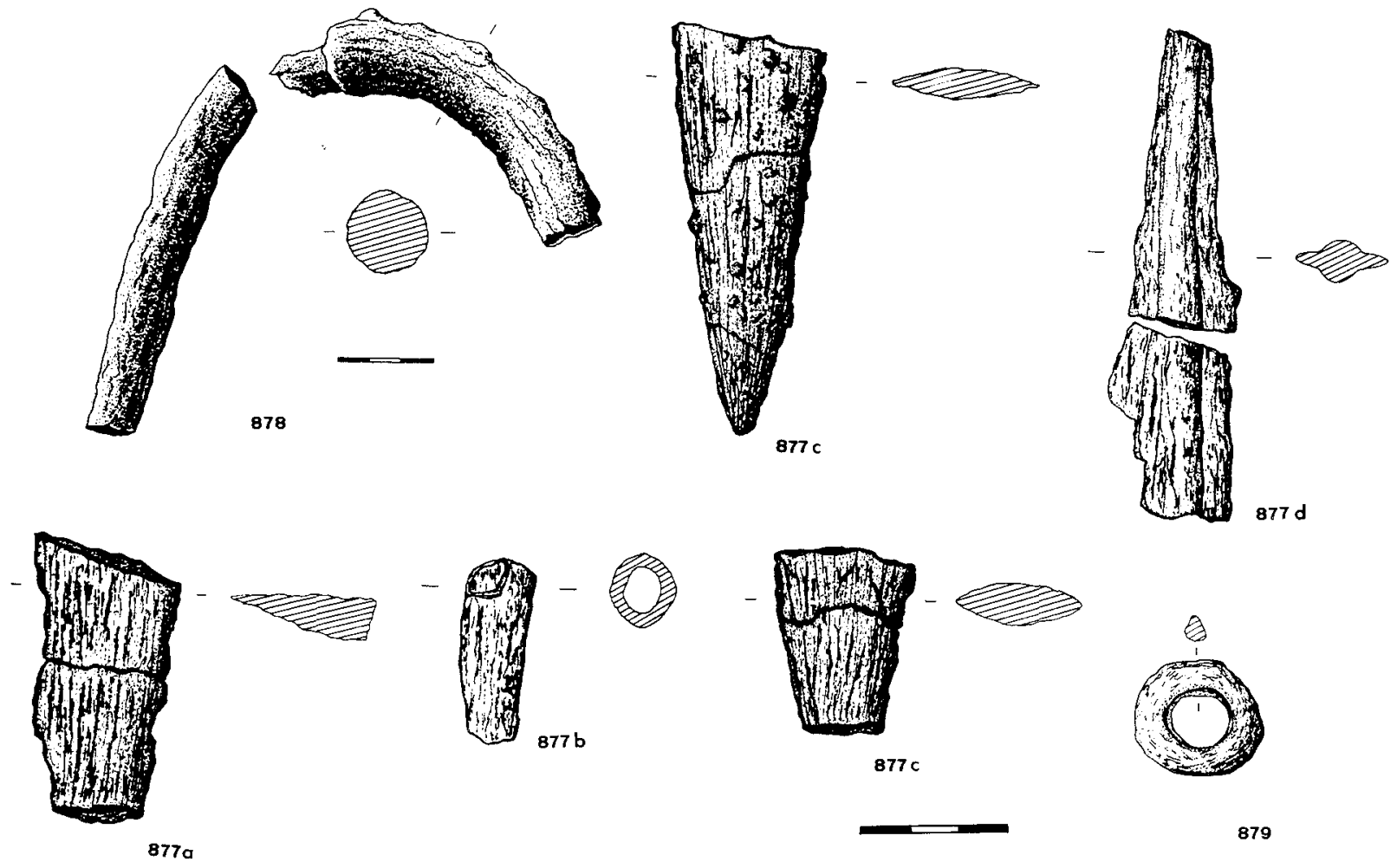

Fig. 13.- Sepultura 10.

plato, puesto que por comparación con el de la Sepuitura 4, se adscribe también a esta cronología (BLÁNQUEZ, 1990, fig. 46).

En esta sepultura contrasta vivamente la cantidad de restos de armamento documentados, respecto de las restantes analizadas: dos espadas rectas o fragmentos de ellas, un fragmento de falcata, un fragmento dudoso de punta de espada o de falcata (número $877 \mathrm{~b}$ ), un soliferreum y una punta de lanza con su regatón.

En el primer grupo destaca la número 876 con una sección ovalada en la parte superior y ovaladaapuntada en la inferior. Tanto en este caso como en el segundo ejemplar, número $877 \mathrm{c}$, no hemos podido descubrir restos de decoración o hendiduras que nos ayuden a establecer su filiación. Sólo podemos apoyarnos en su perfil recto sin estrangulamiento central de la hoja. Con estas características, la práctica totalidad son de antenas, o de frontón, que en el primer caso se fechan entre fines del s. VI a. C. y la primera mitad del s. IV a. C., y en el segundo caso, entre el último cuarto del s. VI y el primero del s. IV a. C.
Para el fragmento de falcata nos remitimos a lo ya expuesto más arriba al hablar del ejemplar de la Sepultura 4. Lo mismo sucede con el fragmento de punta de lanza con nervio central número $877 \mathrm{~d}$, similar al número 841 de la sepultura $5 \mathrm{y}$ con el fragmento de regatón número $877 \mathrm{e}$. Completan el ajuar de armas ofensivas dos fragmentos de soliferrea (número 878). El último elemento que presentamos corresponde a una anilla de hierro (número 879 ).

\section{Sepultura 11 (Fig. 15)}

De este enterramiento sólo se indica la posición del ajuar, señalando que alrededor de la urna se hallaron trozos de falcata, de lanza y un peso de barro; el resto, dentro de ella. La urna presenta perfiles muy semejantes a algunas piezas de La Bastida que aparecen en el Dep. 30, junto a barniz negro de la forma Lamb. 21 y 24 , o en el Dep. 74, con páteras de la forma Lamb. 21/25, 21 y 22 (FLETCHER ET ALII, 1965, 154 y 1969, 143); la encontramos también muy similar en algunas tumbas de 


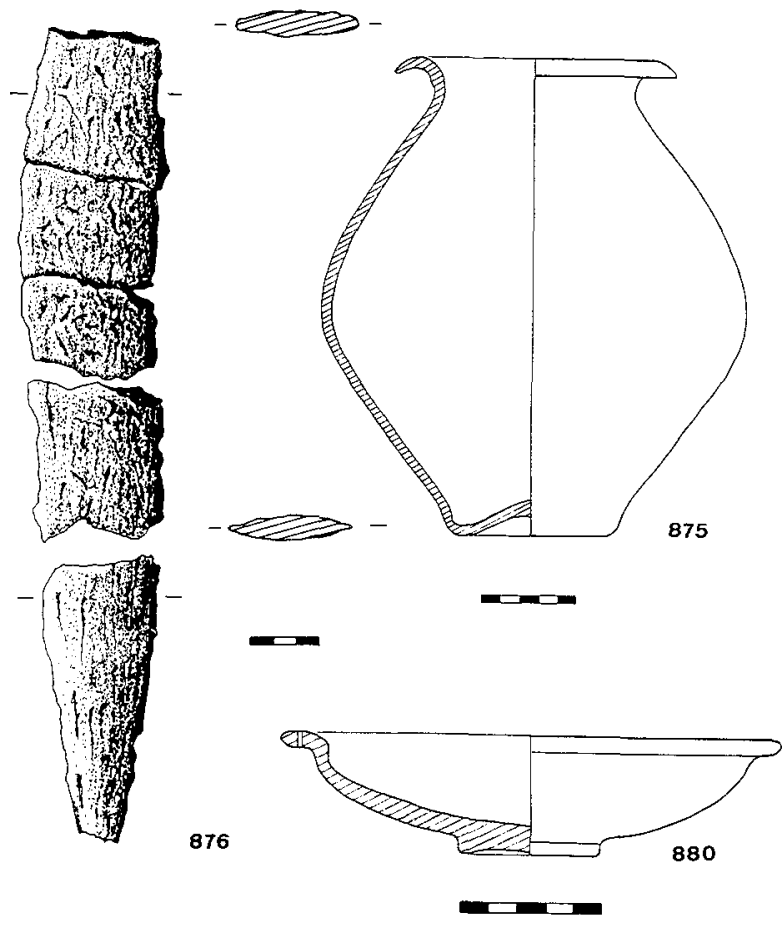

Fig. 14.- Sepultura 10

Baza (PRESEDO, 1982, fig. 1, 37 y 82) y en La Albufereta (Alicante), asociada a una fíbula anular hispánica, como es el caso de esta Sepultura (RUBIO, 1986, fig. 30, Sep. F-72).

El único fragmento de fíbula conservada, perteneciente al resorte de muelle de una anular (número 888), es demasiado pequeño para concretar su fecha. Lo mismo ocurre con el fragmento de falcata número 883 , el resto de soliferreum número $885 \mathrm{~b}$, el fragmento de punta de lanza número 884, o el fragmento de vaina número $885 \mathrm{a}$, hasta el momento el único elemento representante de las fundas de las espadas o falcatas.

En el caso del botón cónico de bronce con 10 apéndices (número 889), el paralelo localizado en la necrópolis de El Navazo (La Hinojosa, Cuenca) está fuera de contexto, por lo que sólo nos sirve la fecha global de uso de dicho yacimiento, primera mitad del s. VI a. C. y el año 400 a. C. (GALÁN GAULNIER, 1980, 154, fig. 21, 7). A pesar de no haber documentado otras piezas similares, no descartamos un uso posterior de este tipo de botón.

Los dos elementos cerámicos que acompañan este enterramiento son un pondus trapezoidal con una perforación en la parte superior (número 887 ) y una pieza triangular con los vértices aplanados y una perforación desplazada del centro, de pasta gris y superficie bruñida, que debió servir como elemento de telar (número 886).

Por lo tanto, podemos fechar esta tumba en el s. IV a. C.

\section{Sepultura 12 (Fig. 16)}

De este enterramiento tampoco se hace mención expresa sobre el tipo de tumba, únicamente que la urna contiene el ajuar y posee como tapadera la mitad inferior de otra urna. Es interesante destacar la existencia de cenizas alrededor de la urna.

La forma de esta urna equivaldría a la variante 6BI que dentro de la tipología cerámica del Alto Guadalquivir, se fecha en el s. IV a. C. (PEREIRA, $1988,157)$. De acuerdo con esta cronología se explica su presencia en la necrópolis del Tesorico (BRONCANO ET ALII, 1985, fig. 62) o en el Cigarralejo (CUADRADO, 1987, tumba 43, fig. 48).

El ajuar metálico se compone exclusivamente de dos fíbulas realizadas en bronce. La primera de ellas (número 892) es una fíbula anular que conserva el pie, perforado para que pase el anillo de sección circular, donde se aprecian restos de la mortaja; conserva asimismo el puente de sección circular, con lo cual se puede encuadrar en el tipo I de Iniesta. Genéricamente podemos pensar que se trata de una anular del tipo 9b de Cuadrado con el puente de varilla (CUADRADO, 1957, 40). En el estudio de Iniesta se presenta un ejemplar perteneciente al Tolmo de Minateda de la colección Reverte del que no se aprecia el resorte (INIESTA, 1983, 169). La fecha estimada por este último autor se encuentra a caballo de los siglos V y IV a. C. (INIESTA, 1983, 252).

La segunda fíbula (número 893) pertenece al grupo de la Téne I, cuyo puente hace que la podamos encuadrar dentro del grupo de arco peraltado, grupo 3 de la clasificación de Cuadrado quien la fecha en los tres primeros cuartos del s. IV a. C. (CUADRADO, 1978, 309 y 329).

\section{Sepultura 13 (Fig. 17)}

Sin otra noticia que la relación de objetos pertenecientes al ajuar, que por otro lado son poco relevantes para obtener cronologías, resulta difícil fe- 

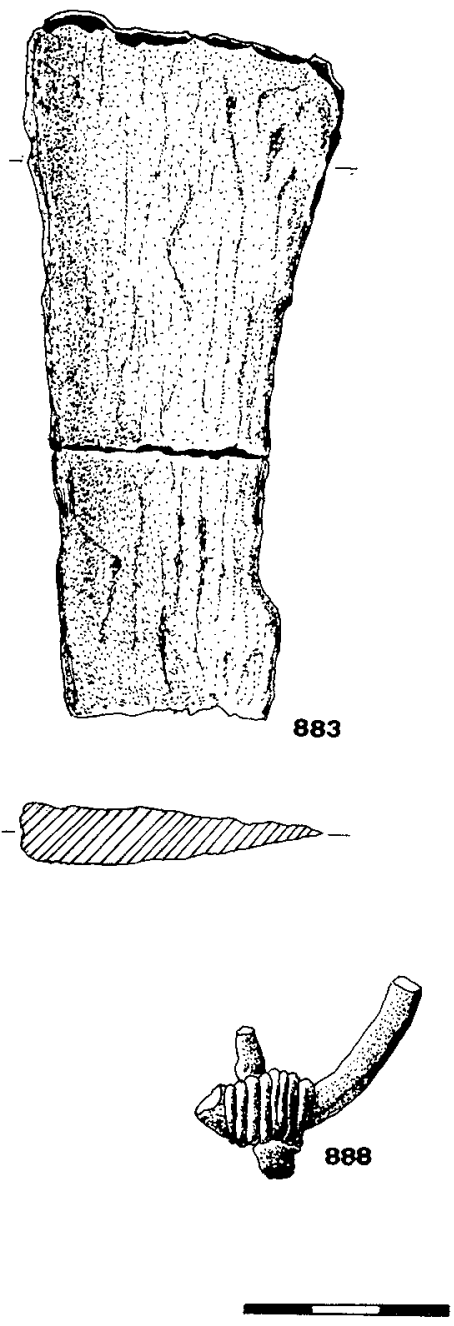

Fig. 15.- Scpultura 11.
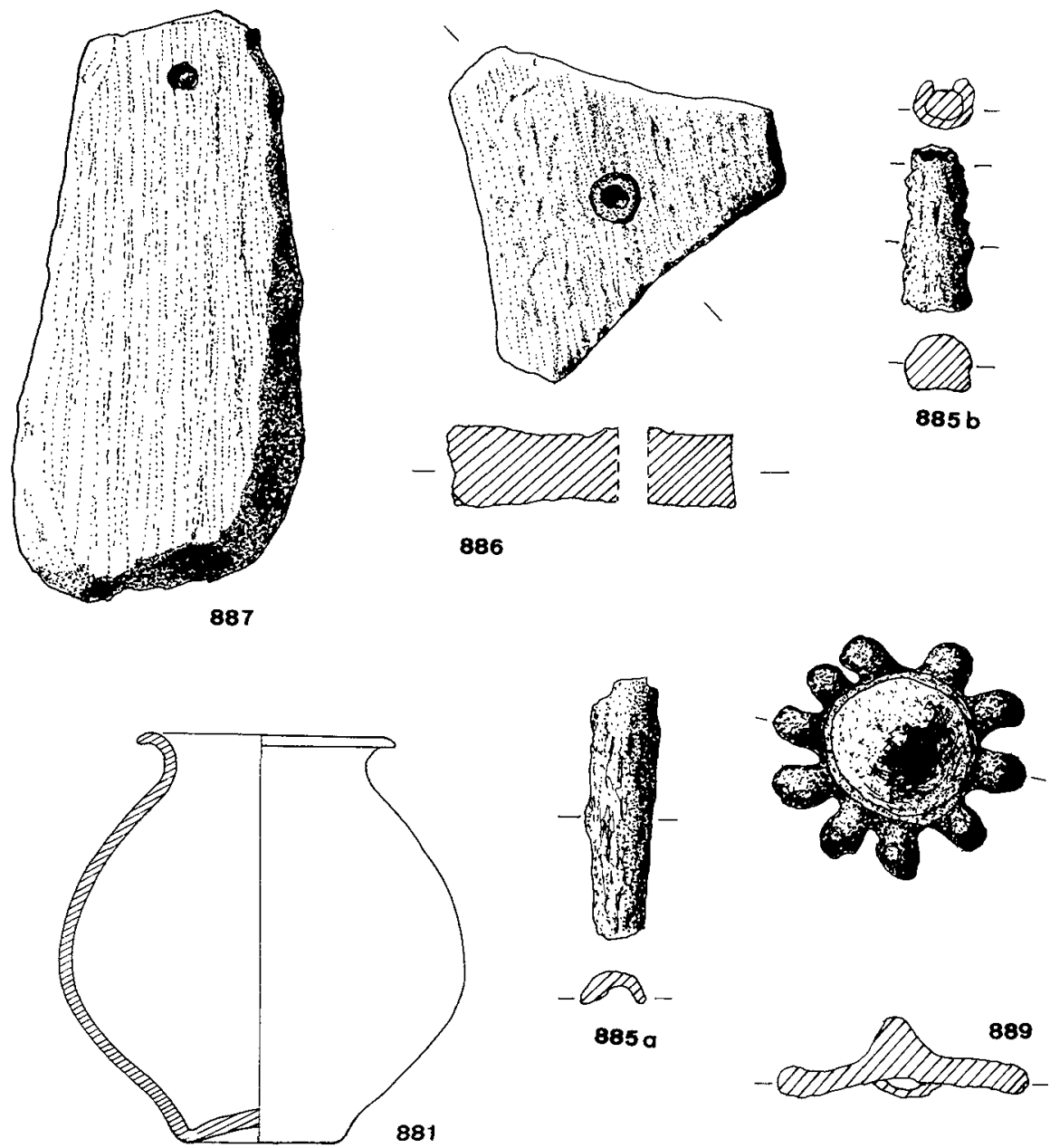

char con certeza este enterramiento. La urna se halló rota habiendo desaparecido su mitad superior. No obstante, siguiendo criterios formales, su forma panzuda similar a la de la Sepultura 11 permitiría encuadrarlo dentro del s. IV a. C.

Los dos fragmentos de punta de lanza con enmangue tubular (número 901) coinciden con la tipología general establecida para otras piezas similares de esta necrópolis. En este caso, el lamentable estado de conservación no permite más precisiones.

Las dos piezas de un bocado de caballo (número $904 \mathrm{a}$ y $904 \mathrm{~b}$ ) tampoco constituyen un elemento cronológico específico.

Completan el ajuar una fusayola decorada con una serie de puntos en forma estrellada (número
899). La pieza número 900 se interpretó en el momento de su adquisición como un tapón de biberón debido al baquetón en resalte que presenta.

\section{Sepultura 14 (5) (Fig. 18)}

Este vaso posee unas características de forma y decoración bastante singulares. Hasta el momen-

(5) Los ajuares de esta sepultura y las tres restantes aparecen en las notas manuscritas de F. de Motos como material hallado fuera de un contexto funerario, pero sin duda pertenecien- 

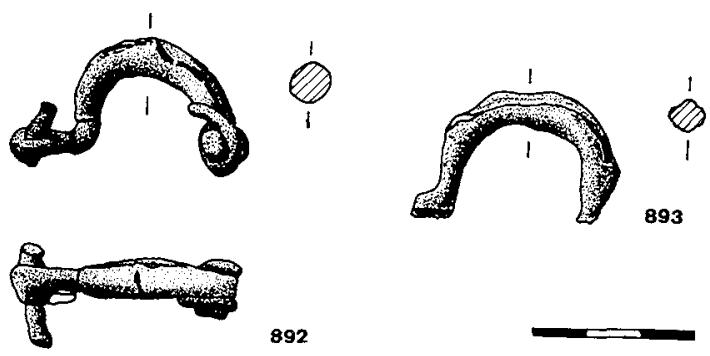

892
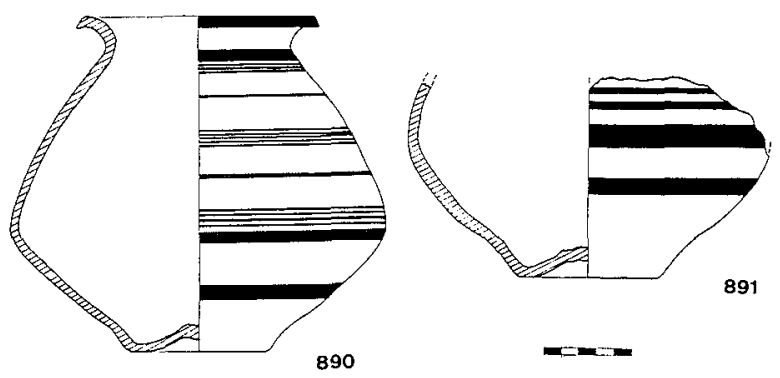

Fig. 16.- Sepultura 12.

to, sólo hemos encontrado paralelos exactos en las tumbas 19 y 122 de la Hoya de Santa. No obstante, en La Serreta (Alcoy, Alicante) existe un vaso que, algo distinto y sin decoración, también con baquetones en el cuello, podría significar ese mismo concepto que contiene el vaso que nos ocupa (NORDSTRÖM, 1973, fig. 17,3). Lo mismo ocurre con un ejemplar de Molinicos (Murcia) que presenta incluso las molduras del cuello decoradas con trazos pintados (LILLO, 1981, MOL. IX, 1).

Aunque algo más alejadas geográficamente, en la necrópolis de Cabrera de Mar hay unas piezas que el autor denomina «jarras con dos asas», tanto en pastas grises como en rojizas más comunes, que si bien difieren un tanto en la forma, recogen esa misma idea. Son materiales que proceden de colección particular, pero por su asociación a cerámica ática y producciones de barniz negro del Golfo de León, se pueden fechar "grosso modo» entre el s. IV y la primera mitad del s. III a. C. (BARBERÁ, 1968, fig. 24 y ss.).

Por todo ello creemos que este vaso de la Sepultura 14 se puede fechar dentro del s. IV a. C. y

tes a la necrópolis. Dada la escasa potencia que presentan los terrenos donde se ubica la necrópolis, sospechamos, sin poderlo asegurar, que se trata de enterramientos arrasados. En cualquier caso, procederemos a analizar los materiales conservando la nomenclatura con la que fueron registrados en el Museo de Albacete.
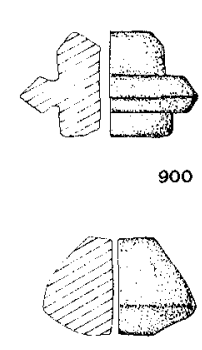

899
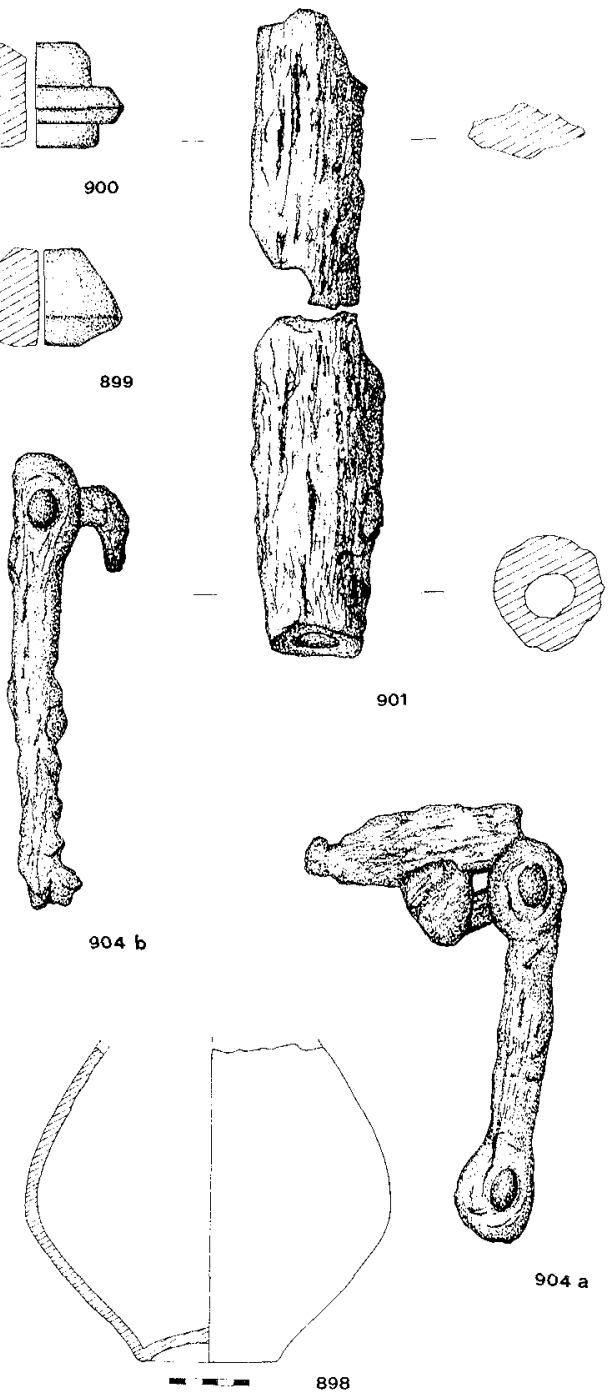

$904 \mathrm{a}$

Fig. 17.- Sepultura 13.

muy posiblemente se trate de una creación ibérica típica de esta zona.

Sepultura 15 (Fig. 18)

En esta sepultura tenemos un vaso que conserva sólo su mitad inferior. Presenta un pie anular y una decoración pintada con series de semicírculos concéntricos que en la cerámica ibérica del Levante aparece entre los s. IV y II a. C. (NORDSTRÖM, 1973, 202).

En cuanto a la forma, creemos que la restitución de su perfil completo sería muy similar a la de 

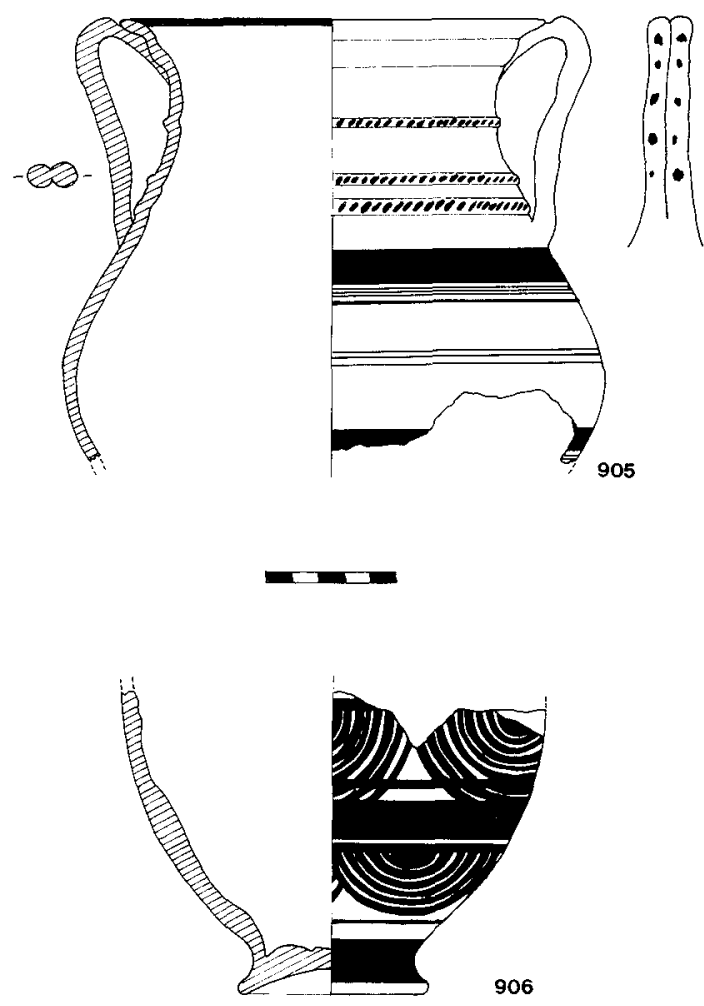

Fig. 18.- Sepultura 14 (n. $\left.{ }^{\circ} 905\right)$ y $15\left(\mathrm{n}^{\circ} 906\right)$.

la urna de la tumba 37 de la Hoya de Santa Ana o a la urna número 80 de la tumba 277 del Cigarralejo, fechada por el barniz negro entre fines del s. V y primer cuarto del s. IV a. C.

Por todo ello podemos fechar este vaso en el s. IV a. C.

\section{Sepultura 16 (Fig. 19)}

Esta sepultura incluye dos vasos, uno de ellos restaurado y otro incompleto. El primero de ellos, con un perfil bicónico, es más difícil de clasificar; sin embargo, la decoración de círculos tangentes pintados es fechada por Nordström en La Serreta y el Tossal de Manises en La Bastida la encontramos de forma abundante entre los s. IV y III a. C. (NORDSTRÖM, 1973, fig. 30, 4 y 5) y también en el s. III a. C. El segundo vaso conserva su mitad inferior, y por su pie anular alto podemos suponer que se trata de una imitación ibérica de una crátera, que durante el s. IV a. C. es uno de los recipientes más apreciados por las comunidades indígenas (PEREIRA, 1988, 162).
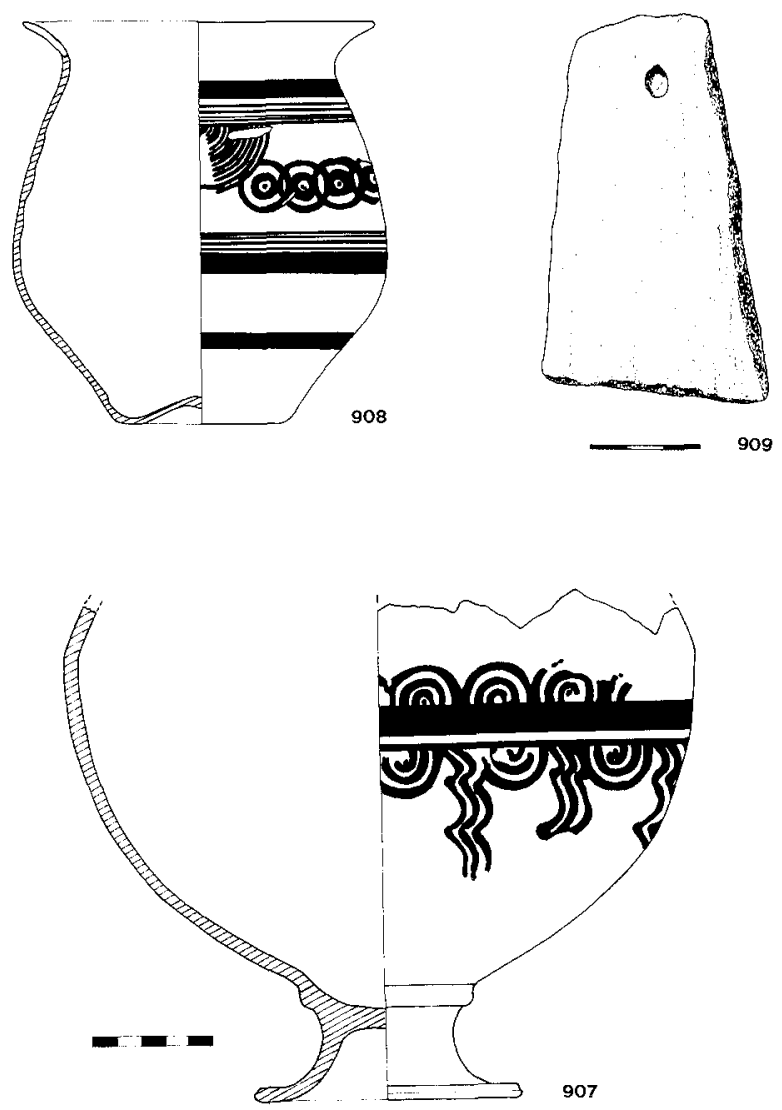

Fig. 19.- Sepultura 16 (n. 907 y 908) y $17\left(n .^{\circ} 909\right)$.

Sepultura 17 (Fig. 19)

Con este registro encontramos únicamente una pesa de telar de arcilla rojiza y forma trapezoidal de difícil datación.

\section{CONCLUSIONES}

$\mathrm{El}$ «Bancal del Estanco Viejo» constituye una de las necrópolis del Tolmo de Minateda. Tradicionalmente se han tenido noticias de hallazgos de inscripciones y otros elementos funerarios en el terreno situado frente a esta necrópolis pero al otro lado del arroyo, justo al pie del Tolmo en su vertiente sur. Por otra parte, ya avanzamos el hallazgo de otra zona de necrópolis durante la campaña de excavaciones de 1989 , todavía en fase de excavación y estudio, que se puede encuadrar en un momento ibérico tardío y alto imperial (fig. 3). De todo ello se 
desprende que los terrenos bajos que rodean el Tolmo de Minateda fueron ocupándose como zonas de enterramientos. Lo que no queda claro de momento es si estos enterramientos se depositaron de forma indiscriminada, o si por el contrario, como sería más lógico, las necrópolis se ubicaron en distintas áreas según las épocas.

En el caso de la necrópolis del «Bancal del Estanco Viejo», el estudio de los ajuares nos ha permitido obtener diversas cronologías que en definitiva suponen distintos momentos de utilización de la misma: de esta manera, nos encontramos con un grupo de tumbas del s. V a. C.; otras fechables en el s. IV a. C., aunque pueden entrar algo en el s. III a. C., y en cualquier caso, suponen una fase ibérica plena diferenciada del s. V a. C.; y por último, un grupo reducido de tumbas que se podrían considerar ibéricas muy tardías o altoimperiales. Las Sepulturas 3 y 7 ofrecen otra problemática. Con respecto a la primera, parece claramente que se han mezclado dos tumbas, una del s. IV a. C. y otra altoimperial, si bien por las notas conservadas es imposible saber si la confusión tuvo lugar durante los trabajos de excavación o al ingresar en el Museo. En la Sepultura 7 aparecen asociadas una urna tipológicamente del s. V y, como tapadera, un plato cuya cronología inicial por paralelos claros es del s. IV a. C.

Resulta curioso observar cómo con una muestra tan escasa (tan sólo 13 tumbas identificadas como tales) se representa un espectro cronológico tan amplio. Esto que en principio podría parecer una mezcla confusa se puede entender si pensamos que lo que se está dando es una estratigrafía horizontal. No sería éste un caso único; tenemos el ejemplo muy cercano y significativo de la Hoya de Santa Ana (BLÁNQUEZ, 1986-87, 14). Con ocasión de una visita a la necrópolis, pudimos comprobar la escasa potencia estratigráfica del terreno que como máximo alcanza unos $50 \mathrm{~cm}$., al tiempo que observamos que el arrastre de agua de unas lluvias recientes había dejado al descubierto amplias zonas de la roca madre, una especie de marga semidescompuesta. Por lo tanto, no sería descabellado pensar que F. de Motos encontró un terreno muy lavado (tal y como se encuentra ahora) lo que le permitió excavar allí donde localizó manchas de cenizas. Así se explicaría esta variada cronología y el que García y Bellido durante el mes de excavación que realizó en la necrópolis en 1942, habiendo trazado dos largas trincheras, sólo encontrará tres tumbas (6).
Por lo que respecta al rito y al tipo de enterramientos es bien poco lo que podemos decir. F. de Motos hace una única distinción en sus notas: por un lado, unos enterramientos de inhumación (Sepulturas 1,2 y 3 ), que por este mismo hecho él considera como romanos, y el resto, de incineración. Trataremos en primer lugar de estos últimos.

F. de Motos da escasa información acerca del tipo de tumbas. No obstante, creemos que no habría tumbas con superestructura de tipo tumular o turriforme, como es frecuente en las necrópolis de la zona, porque en ese caso lo mencionaría de alguna forma. De las descripciones que da para algunas sepulturas se deduce que deben tratarse de enterramientoso simples de cremación en hoyo con urna (Tipo Ib de Blánquez), con el ajuar depositado fuera y dentro de la urna indistintamente. Este tipo de tumba tiene un uso muy amplio, documentadas ya a fines del s. VI a. C. en La Bobadilla (Jaén) (MALUQUER, 1973), en el s. V a. C. en necrópolis como la del Camino de la Cruz, Los Villares, El Molar, por citar algunos ejemplos, llegando hasta el s. IV a. C. en El Cigarralejo, Cabezo Lucero o Puntal de Salinas (Villena), lo que viene a corroborar la cronología asignada a los ajuares.

La existencia de inhumaciones resulta ya más problemática sobre todo por el hecho de hallarse «entre las ibéricas» como afirma el excavador al hablar de la Sepultura 1. El esqueleto de esta tumba pertenece a un niño y lo mismo podría decirse de la Sepultura 2 (aunque F. de Motos afirme que se trata de una mujer adulta de $84 \mathrm{~cm}$.); de la tercera inhumación no da otro dato. En el caso de que fueran las tres inhumaciones de niños sería más explicable su presencia, puesto que a pesar de la generalización del rito a mediados del s. II de nuestra Era, las inhumaciones de niños no son hechos aislados durante el s. I d. C. Hemos fechado estos enterramientos en época altoimperial por paralelos con cremaciones excavadas durante la campaña de 1989 en la necrópolis del Tolmo, descubierta recientemente. Con todo, la respuesta a esta cuestión nos la proporcionará la continuación de los trabajos de campo en esta necrópolis, donde ya se han documentado dos inhumaciones de niños fechadas en la primera mitad del s. I a. C. por la cerámica campaniense que los acompaña.

(6) Estos tres enterramientos no han sido localizados, ni hay constancia de su ingreso en los fondos del Museo de Albacete. 
En resumen, en el yacimiento del «Bancal del Estanco Viejo» tenemos una de las necrópolis del Tolmo de Minateda que sirvió como tal al menos desde el s. V a. C., continuando en época ibérica plena, y, salvo un «hiatus» en época ibérica tardía, se atestigua su utilización aún en fechas altoimperiales. Es comprensible pensar que un área sacralizada de antiguo con un carácter funerario, continúe como tal en la memoria colectiva de los habitantes del núcleo urbano correspondiente, bien por vínculos de parentela o filiación social, bien por relaciones del tipo de la «fides» ibérica (ALMAGRO, 1983, 727-728, 730). No obstante, se ha documen tado la destrucción de tumbas por la construcción de enterramientos posteriores, como ocurre en Toya (FERNÁNDEZ-MIRANDA y OLMOS, 1986), o en Puente del Obispo (RUIZ ET ALII, 1984, 231) lo que plantea. El interrogante de si al producirse esta destrucción, el espacio funerario anterior quedaría asumido en la nueva tumba (PEREIRA, 1987, 267).

Desconocemos si las tumbas de la necrópolis del «Bancal del Estanco Viejo» tuvieron una cubierta de adobes o de barro de color ocre, a falta de empedrados tumulares. Sin embargo, cuenta con todos los restantes elementos que caracterizan las necrópolis de la zona comprendida entre el SE de Albacete, Alicante, Murcia y sur de Valencia, y nos permiten adscribirla en la dinámica del mundo funerario que funciona de manera idéntica en toda esta región: cremación, empedrados tumulres, falcata como arma fundamental acompañada de soliferreum varios tipos de armas y escudos muy similares (CUADRADO, 1987, 185, 199 y 200). Este aire de familia que las une las diferencia en cambio con las necrópolis de la Alta Andalucía, que cuentan a su vez con otros elementos que parecen delimitar un área con personalidad propia, con un «paisaje funerario» y una estructura social distintos (PEREIRA, 1987, 267; RUIZ, 1978).

Pese a esta distinción, sí parece haber un vínculo bastante claro entre ambas regiones, vínculo que se debe establecer a través de las vías de penetración que significan los ríos Segura y Mundo hacia el SE de Albacete, y desde aquí, a través del Guadalimar, hacia la cuenca alta del Guadalquivir. El estudio de la cerámica ibérica de esta zona del valle permite descubrir una clara diferencia entre el sector occidental y el oriental a partir del s. V a. C.: un sector occidental que acusa un declive desde mediados del s. VI a. C. (caída de Tiro, empobreci- miento de las minas de Huelva, cese de las importaciones griegas...) frente a un sector oriental que ofrece un despegue desde el $\mathrm{s}$. $\mathrm{V}$ y un apogeo en el s. IV a. C., en función del traslado de la explotación minera al área jienense y SE peninsular (PEREIRA, 1989, 152, fig. 2, 3 y 4). Esta ruptura y posterior despegue se traduce en creaciones cerámicas muy peculiares de la zona oriental como el «Vaso chardon» o las urnas de orejeta en el s. V a. C., o las imitaciones de recipientes áticos (en especial, las cráteras para el mundo funerario) durante el s. IV a. C. (PEREIRA, 1989, 154). Un breve repaso por los yacimientos del SE y Levante peninsular (incluyendo aquí la necrópolis del «Bancal del Estanco Viejo» y el Tolmo de Minateda) nos demuestra cómo este área participa también de estas creaciones cerámicas que, además de otros elementos, parecen ser un indicador de un momento cultural ibérico común a las regiones del Alto Guadalquivir y SE español.

Queda por último señalar la relación que tiene esta necrópolis con otras de la provincia de Albacete en función de un aparente «ordenamiento» de estos espacios respecto de sus poblados y de las vías de comunicación. Al igual que pasa con la necrópolis de «El Tesorico» (BRONCANO ET ALII, 1985), se encuentra al pie de su hábitat correspondiente y además los dos cementerios debieron de situarse cerca de la vía de comunicación que une los dos yacimientos, camino que proviene de la zona de Cieza-Calasparra (Murcia) y se dirige al norte por diversos ramales.

En el caso de las demás estaciones conocidas todas se encuentran al pie de una vía, ya sea de carácter principal o secundaria, como por ejemplo la Hoya de Santa Ana (Chinchilla) (SÁNCHEZ JIMÉNEZ, 1943 y 1947), el Llano de la Consolación (Montealegre del Castillo) (Idem, 1947), Pozo Moro (Chinchilla) (ALMAGRO GORBEA, 1983), si bien en ninguno de estos casos se tiene localizado el poblado.

En el conjunto de las necrópolis conocidas en la provincia en estudio, las únicas que no presentan restos de construcciones tumulares son la del Camino de la Cruz (Hoya Gonzalo) (BLÁNQUEZ, 1984), y la del Bancal del Estanco Viejo, si bien en el primer caso la cronología puede circunscribirse al primer cuarto del siglo $\mathrm{V}$ a. de $\mathrm{C}$., mientras que en el segundo la amplitud cronológica es mucho mayor. 
Sobre el hecho de que Motos no cite superestructuras de tipo tumular cubriendo alguna de las cremaciones, y suponiendo que se mencionarían de haber existido, caben dos posibilidades: la primera explica este detalle sobre la base de una diferenciación espacial de las diversas categorías sociales, reflejadas en sus espacios mortuorios sacralizados; la segunda lo explica en el caso de que consideraramos a estos enterramientos anteriores a la implantación del modelo de túmulos, que se generaliza a partir de fines del siglo $\mathrm{V}$ a. de $\mathrm{C}$. en relación más que probable con la «crisis» que venimos detectando en el espacio comarcal en estudio. Se expresa en una destrucción sistemática de los poblados amurallados que caracterizan las fases del Hierro Antiguo y el ibérico inicial, dos aspectos íntimamente relacionados que no se pueden separar. Esta destrucción (Cerro Fortaleza en Fuente Álamo y Los Almadenes en Agramón-Hellín, descubiertos recientemente) debió de estar acompañada de un arrasamiento en los niveles correspondientes a las necrópolis contemporáneas, que se aprecia sobre todo en la destrucción de algunos de los pilares-estela conocidos y también en el monumento de Pozo Moro, ya que fragmentos de estas construcciones se reaprovechan en los túmulos que se construyen posteriormente.

En lo que se refiere al análisis del ajuar metálico (cuadro 1) se da la circunstancia de que en todos los casos las sepulturas presentan algún tipo de arma, ya sean cortas (falcatas o espadas, además de los cuchillos), como arrojadizas, es decir, lanzas, jabalinas o soliferrea.

Asimismo interesa destacar, aunque la muestra es reducida (10 sepulturas), que en el caso de la presencia de bocados de caballo (sepulturas 5, 8, 10 y 13) se tiene asociada un arma arrojadiza a excepción de la número 8 . Y también se da en común un arma corta con otra arrojadiza en cinco ocasiones (sepulturas 5, 7, 9, 10 y 11), mientras que en cuatro, una u otra son excluyentes (sepulturas 4, 6, 12 y 13), quedando un solo ejemplo, sepultura 8 , en donde se da el arma corta de pequeño tamaño (cuchillos rectos o afalcatados).

Las veces que aparece la fusayola en los enterramientos siempre lo hace en aquellos en donde las armas son características (sepulturas 4, 5, 6 y 13, un pondus en la número 11), y en el caso de la número 8 no aparecen, lo que nos está indicando, en nuestra opinión, que no tienen por qué reflejar una relación entre un oficio, tejedores y un sexo determinado, las mujeres. Tal vez se pudiera ver como un reflejo del rito en que se simboliza el tejido a través de las fusayolas. De esta manera creemos que se puede establecer una relación arma-sexo masculino, que se confirma tanto en las fuentes como en las representaciones iconográficas conocidas, y que por el contrario, la presencia de fusayolas no es necesariamente un índice de sexo femenino.

\section{ADDENDUM}

Presentamos aquí los materiales procedentes del cribado de las terreras de la canalización que atraviesa el área de la necrópolis. Aparte de varios fragmentos informes de cerámica ibérica, lo más destacable son dos fusayolas decoradas y varios fragmentos de cerámica ática de barniz negro (Fig. 20).

Las fusayolas son idénticas en cuanto a forma, tamaño y decoración. Ambas están realizadas con una pasta de color gris oscuro, y con un tratamiento final bruñido. La decoración consiste en unos trazos incisos en espiga situados en el remate cilíndrico superior, y unos motivos impresos dispuestos de forma radial en la parte superior del cono. Estos motivos representan hojas, de factura bastante esquemática, con un tallo central del que parten las nervaduras típicas.

Esta peculiar decoración, que por otro lado no es muy frecuente sobre fusayolas, caracteriza la pro-
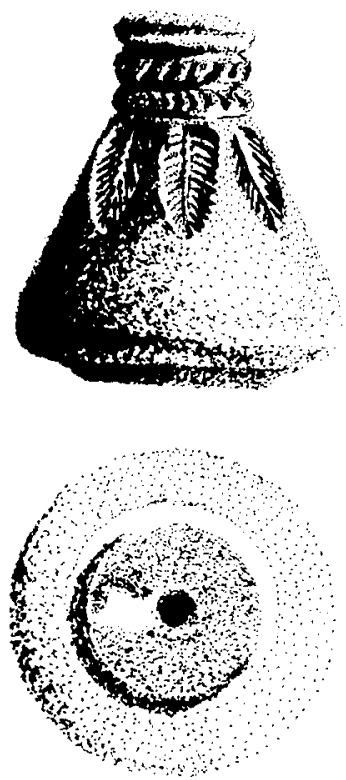

Fig. 20 . 
CUADRO 1. AJUAR METÁLICO DE LAS SEPULTURAS IBÉRICAS

\begin{tabular}{|c|c|c|c|c|c|c|c|c|c|c|}
\hline & S. 4 & S. 5 & S. 6 & S. 7 & S. 8 & S. 9 & S. 10 & S. 11 & S. 12 & S. 13 \\
\hline Falcata & & $1 p$ & & $21 \mathrm{p}$ & & 1 & 1 ó 2 & 1 & & \\
\hline Espada & & & & & & & 2 ó 3 & & & \\
\hline C. afalc & & & & & 1 & & & & & \\
\hline Cuchillo & & & & & 1 & & & & & \\
\hline Solifer & 1 & & $1 ?$ & & & 1 ó 2 & 1 & 1 & & \\
\hline Lanza & & 1 & $1 ?$ & 1 & & $1 ?$ & 1 & $1 \mathrm{p}$ & & 1 \\
\hline Regatón & & 1 & 1 & $2 ?$ & & & 1 & & & \\
\hline An. esc & & 4 & & & & & & & & \\
\hline Bocados & & 2 & & & 1 & & $1 ?$ & & & 2 \\
\hline Vaso br & & & & & & 1 & & & & \\
\hline Broche br & & & & & & & & 1 & & \\
\hline Pulseras & & & & & 1 & & & & & \\
\hline Anillos & & & & & & & & & & \\
\hline Fíbulas & 1 & 5 & $21 \mathrm{p}$ & & 3 & & & & 2 & \\
\hline
\end{tabular}

CUADRO 2. CRONOLOGÍA DE LAS SEPULTURAS

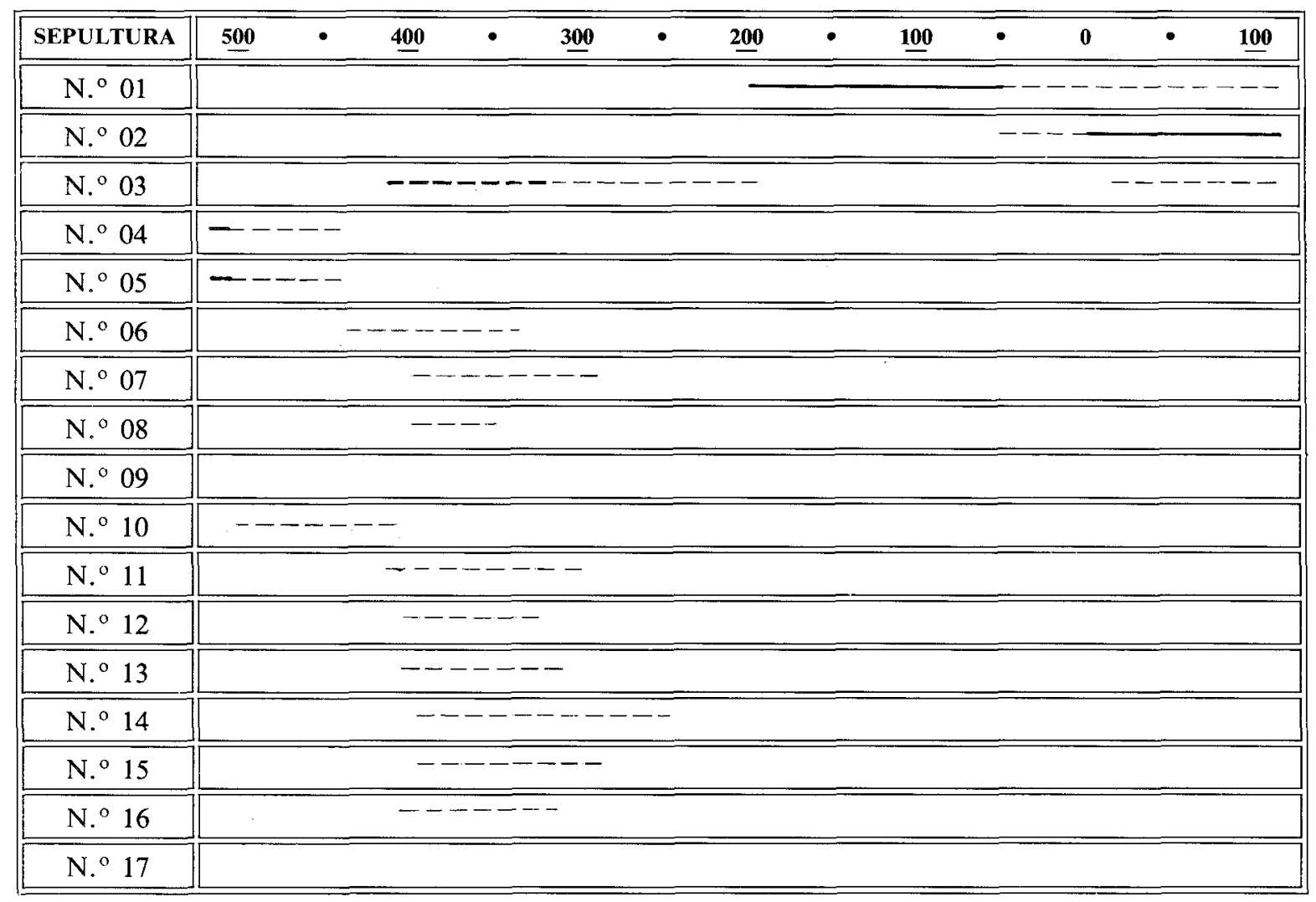


ducción de cerámica ibérica estampillada, ampliamente representada en la Alta Andalucía, Meseta Oriental, interior del País Valenciano, Murcia y Cataluña. Las tres primeras áreas son las que más nos interesan por su relación geográfica con la necrópolis objeto de este estudio. En este sentido, es significativo señalar la existencia de este motivo en hoja, idéntico o muy similar, en las zonas reseñadas (MATA, 1985, fig. 4, 27; 5, 28; RUIZ Y NOCETE, 1981, fig. 3, 20, 22, 23 у 25, 379).

Este tipo de cerámica se fecha desde mediados del s. IV a. C. en el Alto Guadalquivir hasta fines del s. III a. C. (RUIZ Y NOCETE, 1981, 355), mientras que en algunos poblados valencianos la cronología puede remontar hasta el s. V a. C. (MATA, 1985, 178). Esta fecha más alta podría corresponder al tipo de fusayola, puesto que con la misma forma la encontramos en las fases II y III de Los Villares (Caudete de Las Fuentes, Valencia) (7), en La Bastida (Valencia) y en la necrópolis de Orleyl (Vall d'Uxó, Castellón) (LÁZARO ET ALII, 1981, fig. 4, 3). Idénticas fusayolas forman parte del ajuar de la tumba 200 de El Cigarralejo, fechada entre 425 y 375 a. C. (CUADRADO, 1987, fig. 150).

En cuanto a la cerámica de barniz negro, los cuatro fragmentos recuperados pertenecen a la categoría de las áticas. Los tres primeros, un fragmento de asa, un fragmento de borde de kylix con arranque del asa y un fragmento de pie, corresponden a las «Stemless cups» del Agora de Atenas, en su variante grande (SPARKES y TALCOTT, 1970, 101 y 102, fig. 5, número 469-517), fechadas en el s. V a. C. a partir de su segundo cuarto. La cuarta pieza es un fragmento de borde de la forma Lamb. 24 ó 25, forma que se halla ampliamente representada en poblados y necrópolis ibérica, en la primera mitad del s. IV a. C.

A pesar de tratarse de un material fuera de contexto, es interesante resaltar su presencia por dos motivos: en primer lugar, nos da unas cronologías que confirman las ya propuestas al analizar los ajuares; y en segundo lugar, prueban la exisencia de estas cerámicas de importación en la necrópolis. $\mathrm{Al}$ abordar este estudio nos llamó la atención la falta de este tipo de piezas en los enterramientos. Pensamos que quizá existieron, pero que no se incluyeron en el lote vendido al Museo de Albacete.

(7) Agradecemos a la doctora Consuelo Mata Parreño el haber podido consultar su tesis doctoral inédita.

\section{BIBLIOGRAFÍA}

ABAD CASAL, L., 1986: «El Oral». Arqueología en Alicante, 1976-1986. Alicante, pp. 143-145.

- 1987: «El poblamiento ibérico en la provincia de Alicante». Iberos. Actas de las I Jornadas sobre el Mundo Ibérico. (Jaén, 1985), pp. 157-169.

- 1989: «Algunas reflexiones en torno a hábitats, poblados y estructuras domésticas de época ibérica en el sur del País Valenciano" en Colloque International Habitats et structures domèstiques en Mèditerranèe Occidental durant la Protohistoire, Arlés (en prensa).

ALMAGRO GORBEA, M., 1969: La necrópolis de Las Madrigueras. Carrascosa del Campo (Cuenca). BPH 10, Madrid.

- 1977: El Bronce Final y el periodo orientalizante en Extremadura. BPH, XIV. Madrid, 1977.

- 1983: «Paisaje y sociedad en las necrópolis ibéricas». XVI, C. N. A., Murcia, 1982, Zaragoza, pp. 275 y ss.

ARRIBAS, A., 1967: «La necrópolis bastitana del Mirador de Rolando (Granada)». Pyrenae, 3, pp. 67 y ss., Barcelona.

AUBET, M. E., 1975: La necrópolis de Setefilla en Lora del Rio, Sevilla. Barcelona.

- 1976: La cerámica púnica de Setefilla. Studia Archaeologica, 42, Valladolid.

BALLESTER TORMO, I., 1930: «Avance al estudio de la necrópolis ibèrica de la Casa del Monte (Albacete)». Cultura Valenciana, 3-4, pp. 27 y ss., Valencia.

BARBERÁ, J., 1968: «La necrópolis ibérica de Cabrera de Mar (Col. Rubio de la Serna)». Ampurias, XXX, pp. 97-150.

BLÁNQUEZ, J. J., 1984: «Las necrópolis ibéricas de la provincia de Albacete». Congreso de Historia de Albacete, vol. I, pp. 185-209.

- 1986-87: «Notas acerca de una revisión de la necrópolis ibérica de la Hoya de Santa Ana (Chinchilla, Albacete)». Cuadernos de Prehistoria y Arqueología, 13-14. Hom. al Prof. Gratiniano Nieto, vol. II, pp. 9-28, Madrid.

- 1990: La formación del mundo ibérico en el noreste de la Meseta (Estudio arqueológico de las necrópolis ibérica de la provincia de Albacete. Instituto de Estudios Albacetenses, Serie I, número 53, Albacete.

BLÁZQUEZ, J. M., 1975: Cástulo I. NAH, 8, Madrid.

BONET, E. y MATA, C., 1981: El poblado ibérico del Puntal dels Llops. T. V. del SIP, número 71, Valencia.

BRONCANO, S. y BLÁNQUEZ, J., 1985: El Amarejo (Bonete, Albacete). EAE, número 139, Madrid.

BRONCANO, S. ET ALII, 1985: «La necrópolis ibérica de El Tesorico (Agramón-Hellín, Albacete)». NAH, 20, pp. 43-181.

CERDEÑO SERRANO, M. L., 1981: «Sigüenza. Enterramientos tumulares de la meseta oriental». NAH, 11, pp. 189-208, Madrid.

CUADRADO, E., 1957: Problemas de la fibula anular hispánica. Salamanca, 1957.

- 1963: Precedentes y prototipos de la fibula anular hispánica. TP, 7. Madrid.

- 1978: «Fibulas de la Téne en el Cigarralejo». TP, 35, pp. 307-336. Madrid.

- 1987a: «Las necrópolis ibéricas del Levante español». Iberos. I Jornadas sobre el Mundo Ibérico. (Jaén, 1985), pp. 185-203.

- 1987b: La necrópolis ibérica de El Cigarralejo (Mula, Murcia). BPH, vol. XXIII. 
- 1989: La panoplia ibérica de «El Cigarralejo» (MulaMurcia). Col. Documentos Serie Arqueología, 3, Murcia.

CRUZ PÉREZ, L., 1988: «Necrópolis de Los Nietos (Cartagena). Campañas de excavaciones de 1984 y 1985». Excavaciones y prospecciones de la Región de Murcia, pp. 183 y ss., Murcia.

ESTEBAN ORTEGA, J. ET ALII, 1988: La necrópolis del Castro del Castillejo de la Orden, Alcántara (Cáceres). Cáceres.

FERNÁNDEZ-MIRANDA, J. y OLMOS, R. 1986: Las ruedas de Toya (Jaén) y el origen del carro en la Península Ibérica. Museo Arqueológico Nacional.

FLETCHER, E., 1965: La necrópolis de La Solivella (Alcalá de Chivert, Castellón). TV del SIP, número 32, Valencia.

FLETCHER, E. ET ALII,1965: La Bastida de les Alcuses (Mogente, Valencia). TV del SIP, número 24 , vol. I, Valencia.

- 1969: La Bastida de les Alcuses (Mogente, Valencia). TV del SIP, número 25, vol. II, Valencia.

GALÁN SAULNIER, C., 1980: «Memoria de la primera campaña de excavaciones en la necrópolis de El Navazo. La Hinojosa (Cuenca) 1976». NAH, 8, pp. 141-212, Madrid.

HERNÁNDEZ, L., 1990: La necrópolis del Peñón del Rey (Villena, Alicante). Tesis de licenciatura inédita.

INIESTA, A., 1983: Las fibulas de la Región de Murcia. Bibl. Básica Murciana, 15. Murcia.

INIESTA, A. ET ALII, 1987: Sepultura 70 de la necrópolis del Poblado. Excavaciones Arqueológicas en Coimbra del Barranco Ancho, número 1. Consejería de Cultura y Educación de la Comunidad Autónoma de Murcia.

JULLY, J. J. y NORDSTRÖM, S., 1972: «Une forme de cèramique ibèro-languedo cienne: La jarre bitronconique». APL, XIII, Valencia, pp. 93-102.

LÁZARO, A. ET ALII, 1981: Materiales de la necrópolis de Orleyl (Vall d'Uxó, Castellón. TV del SIP, número 70, Valencia.

LILLO, P. A., 1981: El poblamiento ibérico en Murcia. Univ. de Murcia. Acad. Alfonso X el Sabio.

MALUQUER, J. ET ALII, 1973: La necrópolis ibérica de La Bobadilla, Jaén. Serie Programas de Investigaciones Protohistóricas, I. Dep. de Prehistoria y Arqueología, Barcelona.

MATA, C., 1985: «Algunas cerámicas ibéricas con decoración impresa de la provincia de Valencia». Saguntum, 19, pp. 153-181, Valencia.

MOLINA, J. ET ALII, 1976: Coimbra del Barranco Ancho (Jumilla, Murcia). TV del SIP, número 52, Valencia.

MONRAVAL, M. y LÓPEZ, M., 1984: «Restos de un silicernio en la necrópolis ibérica de El Molar». Saguntum, 18, Valencia, pp. 145-162.

NIETO, G., 1947: «La necrópolis hispánica del Cabecico del Tesoro». III CASE, pp. 176 y ss., Murcia.

NORDSTRÖM, S., 1967: Excavaciones en el poblado ibérico de La Escuera (San Fulgencio, Alicante). TV del SIP, número 34, Valencia.

- 1973: La cerámique peinte ibérique de la province de Alicante. Estocolmo.

PADRO, J., 1975: «Los objetos de tipo egipcio de la necrópolis de El Molar (San Fulgencio, Alicante) y su problemática». CPAC, 2, pp. 133-142.

PEREIRA, J., 1987: «Necrópolis ibéricas de la Alta Andalucía». Iberos. I Jornadas sobre el mundo ibérico. (Jaén, 1985), pp. 257-272.

- 1988: «La cerámica ibérica de la cuenca del Guadalquivir. I. Propuesta de clasificación». TP, 45, pp. 143-173.

- 1989: «La cerámica ibérica de la cuenca del Guadalquivir. II. Conclusiones». TP, 46, pp. 149-160.

PLA, D., 1980: Los Villares (Caudete de Las Fuentes-Valencia). TV del SIP, número 68, Valencia.

POVEDA, A. 1988: El poblado ibero-romano de El Monastil. Ayunt. de Elda. Univ. de Alicante.

PRESEDO, F., 1982: La necrópolis de Baza. EAE, 119. Madrid.

RIPOLL PERELLÓ, E., 1988: «Cartas al Abate Henri Breuil referentes al descubrimiento de Minateda (Albacete)». Hom. a Samuel de los Santos, pp. 59-64, Albacete.

ROS, M. M., 1989: Dinámica urbanística y cultura material del Hierro Antiguo en el valle del Guadalentín. Colegio Oficial de Arquitectos de Murcia. Universidad de Murcia.

RUBIO, F., 1986: La necrópolis ibérica de La Albufereta de Alicante. Academia de Cultura Valenciana. Serie Arqueológica, 11. Valencia.

RUIZ, A., 1978: «Los pueblos iberos del Alto Guadalquivir. Análisis de un proceso de transición». C. P. U. G., 3, pp. 255-284.

RUIZ, A. y NOCETE, T. 1981: «Un modelo sincrónico para el análisis de la producción de cerámica ibérica estampillada del alto Guadalquivir». C. P. U. G., número 6, pp. 355383, Granada.

RUIZ, A. ET ALII, 1984: «La necrópolis ibérica Finca Gil de Olid (Puente del Obispo-Baeza) Jaén». C. P. U. G., 9, pp. 195-234.

SÁNCHEZ JIMÉNEZ, J., 1947: Excavaciones y trabajos arqueológicos de la provincia de Albacete, de 1942 a 1946. Informes y Memorias, número 15, Madrid.

SAN VALERO, J. Y FLETCHER, D., 1947: Primera campaña de excavación en el Cabezo del Tío Pío (Archena). Informes y Memorias, 13, Madrid.

SCHÜLE, W., 1969: Die Meseta-Kulturen der Iberischen Halbinsel. MF, 03, 2 vols. Berlín.

SENENT, J. J., 1930: Excavaciones en la necrópolis del Molar. MJSEA, número 107. Madrid.

SPARKES, B. y TALCOTT, L. 1970: The Athenian Agora. Black and plain pottery. The American School of Classical Studies at Athens, Princeton. 